\title{
Residual polymer stabiliser causes anisotropic conductivity in metal nanoparticle 2D and 3D printed electronics
}

Gustavo Trindade ( $\square$ Gustavo.FerrazTrindade@nottingham.ac.uk) University of Nottingham https://orcid.org/0000-0001-6998-814X

\section{Feiran Wang}

University of Nottingham

Jisun Im

University of Nottingham

\section{Yinfeng He}

University of Nottingham

Adam Balogh

University of Nottingham

David Scurr

University of Nottingham https://orcid.org/0000-0003-0859-3886

lan Gilmore

National Physical Laboratory, NiCE-MSI https://orcid.org/0000-0002-0981-2318

Mariavitalia Tiddia

National Physical Laboratory

Ehab Saleh

University of Leeds

David Pervan

University of Nottingham

Lyudmila Turyanska

University of Nottingham https://orcid.org/0000-0002-9552-6501

Christopher Tuck

University of Nottingham

Ricky Wildman

University of Nottingham https://orcid.org/0000-0003-2329-8471

\section{Richard Hague}

University of Nottingham

\section{Clive Roberts}

University of Nottingham 


\section{Article}

Keywords: Printed Device Conductivity, Electrical Resistivity Tests, Morphological Analysis, Nanoscale Chemical Analysis, Nanomaterial Ink Formulations

Posted Date: October 29th, 2020

DOI: https://doi.org/10.21203/rs.3.rs-86443/v1

License: (c) (i) This work is licensed under a Creative Commons Attribution 4.0 International License.

Read Full License

Version of Record: A version of this preprint was published at Communications Materials on May 11th, 2021. See the published version at https://doi.org/10.1038/s43246-021-00151-0. 


\section{Residual polymer stabiliser causes anisotropic conductivity in metal nanoparticle 2D and 3D printed electronics}

Gustavo F. Trindade ${ }^{*}, 2$, Feiran Wang ${ }^{2}$, Jisun $\mathrm{Im}^{2}$, Yinfeng $\mathrm{He}^{2}$, Adam Balogh', David Scurr', Ian Gilmore ${ }^{3}$, Mariavitalia Tiddia ${ }^{3}$, Ehab Saleh2,4, David Pervan², Lyudmila Turyanska², Christopher J. Tuck², Ricky Wildman², Richard Hague ${ }^{2}$, Clive J. Roberts* ${ }^{*}$

${ }^{1}$ Advanced Materials and Healthcare Technologies, School of Pharmacy, University of Nottingham, University Park, Nottingham, NG7 2RD, UK

${ }^{2}$ Centre for Additive Manufacturing, Faculty of Engineering, University of Nottingham, Jubilee Campus, Nottingham, NG7 2RD, UK

${ }^{3}$ National Physical Laboratory, Hampton Road, Teddington TW11 OLW, UK

${ }^{4}$ School of Chemical and Process Engineering, University of Leeds, Leeds, LS2 9JT, UK

\section{"CORRESPONDING AUTHOR(S):}

Gustavo.FerrazTrindade@nottingham.ac.uk and Clive.Roberts@nottingham.ac.uk

ABSTRACT: Inkjet printing of metal nanoparticles (MNPs) allows for design flexibility, rapid processing and enables 3D printing of functional electronic devices through codeposition of multiple materials. However, the performance of printed devices, especially their conductivity, is lower than those made by traditional manufacturing methods and is previously not fully understood. Here, we revealed that anisotropic electrical conductivity of printed MNPs is caused by organic residuals from MNPs inks. We employed a combination of electrical resistivity tests, morphological analysis and novel 3D nanoscale chemical analysis of printed devices using silver nanoparticles (AgNPs) to show that the polymer stabiliser polyvinylpyrrolidone (PVP) tends to concentrate between vertically stacked AgNPs layers as well as at dielectric/conductive interfaces. The understanding of organic residues behaviour in printed nanoparticles reveal potential new strategies to improve nanomaterial ink formulations for functional printed electronics. 


\section{Introduction}

Digitally printed electronics are a driver for novel research in various fields owing to their design flexibility as well as other advantages such as expedited time-to-market. ${ }^{1-3}$ Ink jetting of inks containing colloidal materials, such as metal nanoparticles (MNPs), ${ }^{4-8}$ germania-silica, ${ }^{9}$ and semiconductor quantum dots ${ }^{10}$ has been successfully employed in applications ranging from flexible and wearable electronics ${ }^{11-19}$ to quantum optoelectronic devices ${ }^{20-22}$ and fully printed perovskite solar cells. ${ }^{23-26}$ However, the performance of printed parts is not competitive with those made by traditional manufacturing methods. This is due to challenges in both manufacturing techniques and choices of materials, of which there is a lack of comprehensive understanding. MNPs are among the most commonly used conductive materials for printed electronics, and typically require consolidation via a two-step process: solvent evaporation upon printing (pinning) and subsequent low-temperature sintering $\left(120-200^{\circ} \mathrm{C}\right),{ }^{4,14,27-30}$ enabling conductive tracks on polymer substrates. ${ }^{4,7,13}$ More recently, inkjet-based 3D printing has been used to enable the selective co-deposition of different functional materials contemporaneously (i.e. dielectric and/or conductive materials), $4,5,27,31-33$ to ultimately achieve the production of macroscopic multi-material objects with multiple functionalities.

Despite significant interest in utilising MNP-based materials in 2D and 3D printed electronic devices, the lower and anisotropic intra-layer (planar) and inter-layer (vertical) conductivity of MNP layers, compared to bulk metals, limits device performance and hence uptake in industry and products. ${ }^{4}$ The conductivity of MNPs layers are known to be dependent on sintering temperature and have been previously attributed to morphological changes and possible organic residues.,30,34 However, the detailed mechanism of low-temperature sintering of MNPs that leads to reduced conductivity remains to be fully understood.

Organic molecules are used in MNPs inks as stabilisers or capping agents to enable particle dispersion in low viscosity solvents, however, their residues are likely to hinder device performance, ${ }^{34}$ even when present in very small amounts. Surface sensitive chemical analysis techniques of time-of-flight secondary ion mass spectrometry (ToFSIMS) and X-ray photoelectron spectroscopy (XPS), in combination with gas cluster ion beams (GCIBs), are a powerful toolset for depth profiling organic materials with high 
chemical specificity, sensitivity, and nanometre depth resolution, ${ }^{35-42}$ chemical imaging of buried hybrid organic/inorganic interfaces ${ }^{43,44}$ and characterisation of core-shell structures. ${ }^{45-51}$

Here, we present a comprehensive study of the effect of the organic residues, such as stabilisers, and their localised distribution at the interface between printed layers on the functional performance of the printed devices before and after low-temperature sintering. Our results provide new insights on routes to improve intra-layer AgNPs sintering and overcome functional anisotropy and hence improve uptake of this potential transformational technology. Our methodology is transferable to other nanomaterialbased inks and relevant for the development and exploitation of both 2D and 3D printed electronics.

\section{Results}

\section{Distribution of polymer stabiliser upon printing of AgNPs}

To investigate the interface of AgNPs during the inkjet printing and pining process, we carried out high resolution chemical analysis of samples under a selection of printing conditions. As a result, we have found polyvinylpyrrolidone (PVP) on the surface of printed layers of AgNPs by means of the unambiguous identification of characteristic PVP signal ${ }^{36,52}$ using a novel 3D orbiSIMS instrument ${ }^{53}$ and XPS (Fig. 1 and Supplementary Fig. S1). PVP is a commonly used stabiliser, reducing agent, and shape-controlling agent for the synthesis of metal nanoparticles. ${ }^{54,55}$ As a capping agent, it makes MNPs disperse well in aqueous and organic solvents due to its amphiphilic characteristics derived from the highly polar amide group within the pyrrolidone ring and hydrophobicity from the methylene backbone. PVP thus plays a vital role in dispersing and stabilising the MNPs in the solvents for stable ink formulation. ${ }^{56}$ However, PVP does not completely decompose under typical multi-material jetting and sintering temperatures (up to $150^{\circ} \mathrm{C}$ ) ${ }^{5}$ and its residues are likely to remain. Understanding the state and distribution of PVP upon inkjet printing and post-deposition treatment of AgNPs is essential to develop solutions that minimise its impact on the performance of printed electronics. 
a

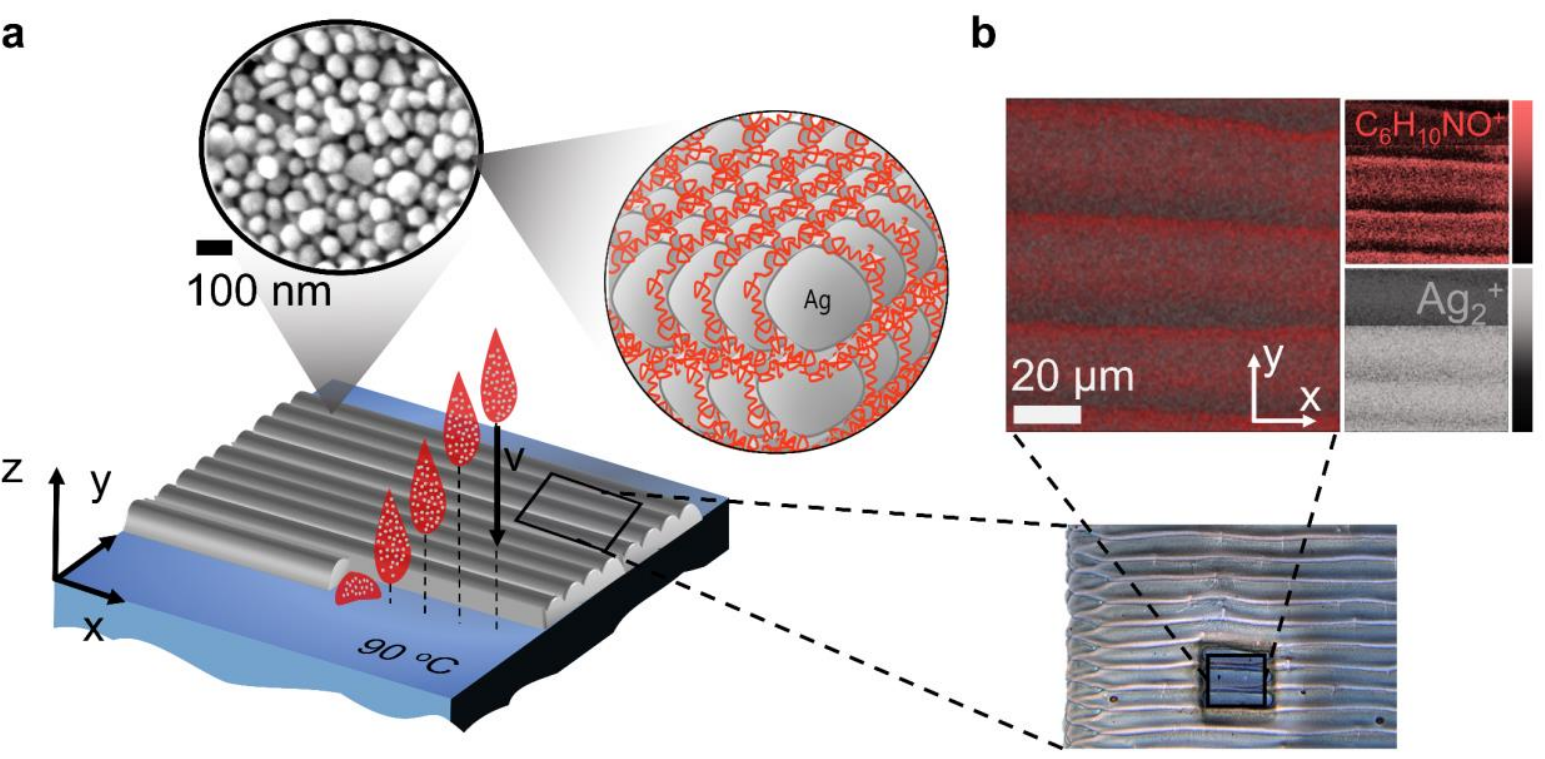

C

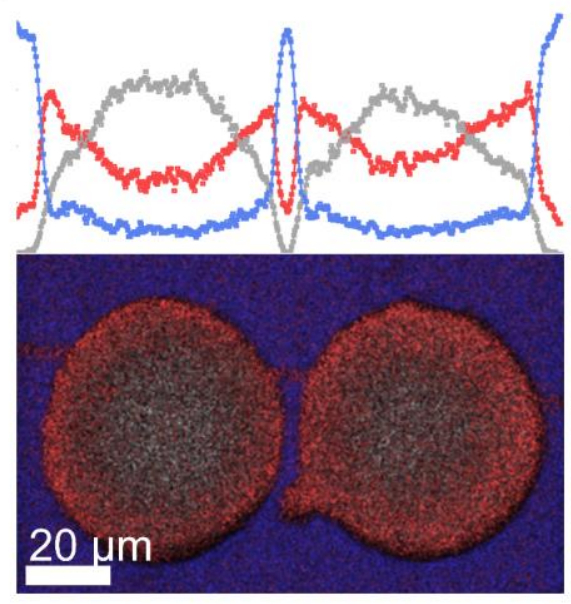

d

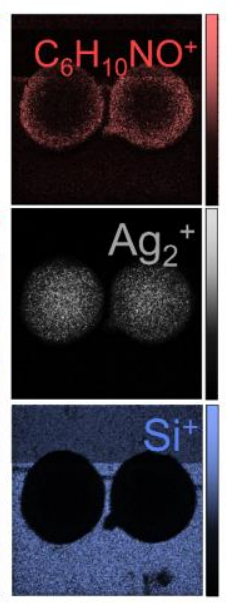

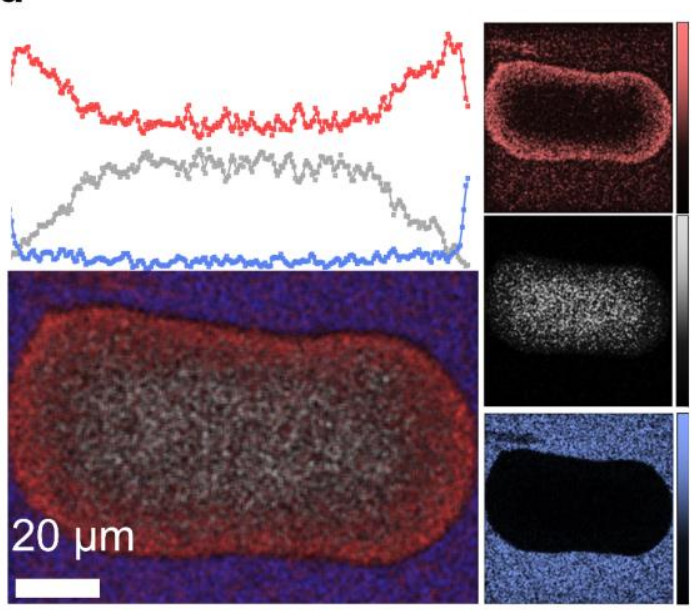

Fig. 1 inkjet printing AgNPs and detection of polymer stabiliser. a Drop-on-demand jetting of inks containing AgNPs with in-situ solvent evaporation (pinning). b Optical image (bottom) of a printed layer of AgNPs and chemical maps (top) showing the distribution of $\mathrm{Ag}_{2}{ }^{+}$(grey), $\mathrm{C}_{6} \mathrm{H}_{10} \mathrm{NO}^{+}$ (red) and $\mathrm{Si}^{+}$(blue) at the surface of a printed layer, c pair of deposited droplets and $\mathbf{d}$ two coalesced droplets. The line plots represent the intensity across the centre of each map.

Inkjet printing of AgNPs starts with printing and then pinning the material by removing the solvent (Fig. 1a). All printing was conducted on a hot stage at $90^{\circ} \mathrm{C}$, which is sufficient for pinning the printed ink without triggering AgNPs sintering. This temperature is also low enough to prevent printhead damage and polymeric substrate degradation. The chemical 
mapping data from the top surface of a printed layer of AgNPs (Fig. 1b) and individually deposited droplets (Fig. 1c-d) show a 'coffee ring' effect where the solute (PVP) and suspending MNPs tend to flow towards its pinned contact line following the outward flow initiated by the combination of evaporation and contact-line pinning effect. ${ }^{57,58}$ This is observed as a pattern with PVP-rich lines at the edge of each swath of MNPs ink across the entire surface(Fig. 1b). ${ }^{57,59}$ The presence of PVP, even if at very low concentrations, can hinder the sintering of MNPs at the interface, leading to reduced conductivity in the inter-layer (vertical) direction. ${ }^{4}$ In a 3D printing context, subsequently deposited AgNPs layers will therefore encounter a PVP-rich surface and these organic molecules may become trapped at the interface. We examined the three-dimensional distribution of PVP, via ToF-SIMS depth profiling, within a sample consisting of four successively printed layers of AgNPs ink. The results (Fig. 2a-b) show that the top surface has the strongest PVP signal intensity, and that PVP signal was also detected through the bulk. Moreover, the PVP intensity oscillates with an average period of $282.8 \mathrm{~nm}$ and peaks at approximately 300, 600 and $900 \mathrm{~nm}$ depth (confirmed by fast Fourier transforms in Supplementary Fig. S5a) which, based on the single layer data (Supplementary Fig. S2), are the depths at which printed layer interfaces are expected to be located. This is consistent with our hypothesis that PVP concentrates at the interface between printed layers (Fig. 2d) and suggests that this happens during the layer-wise printing process. 


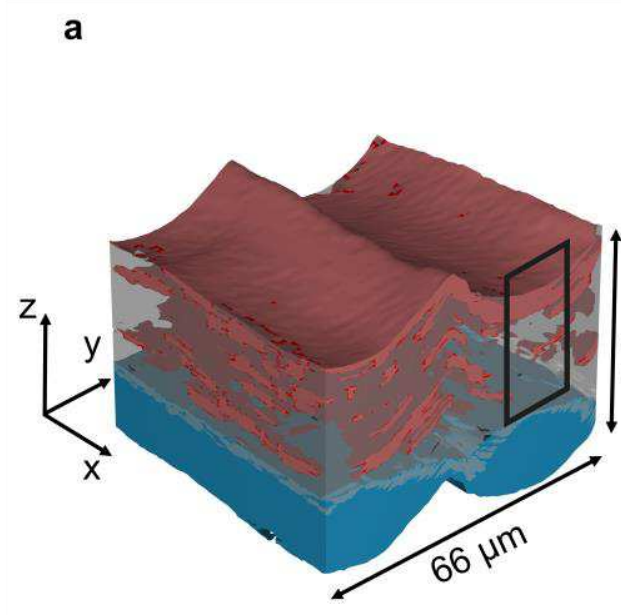

C

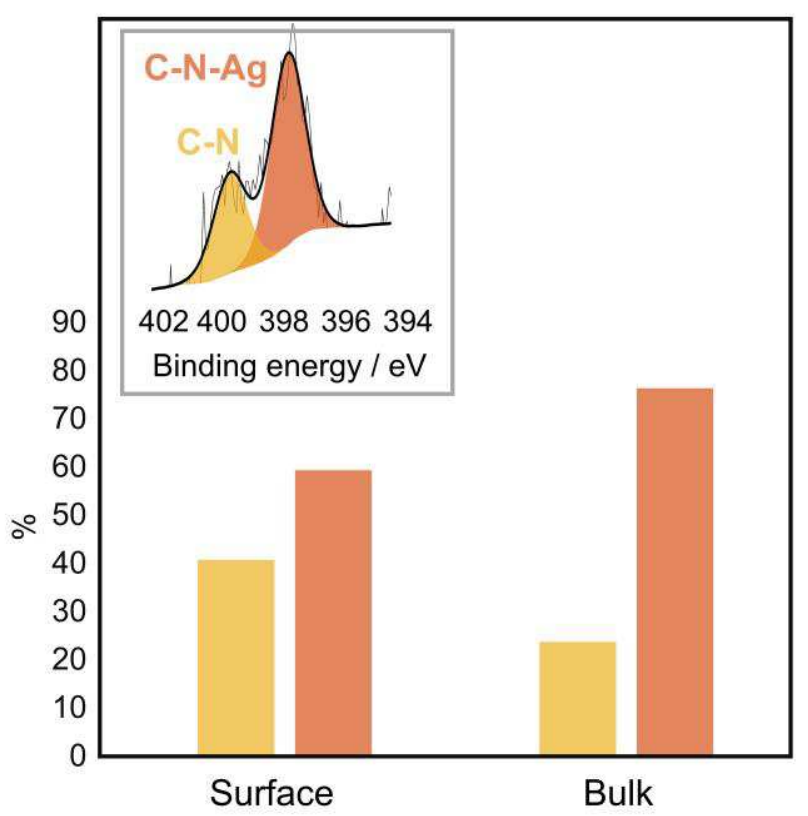

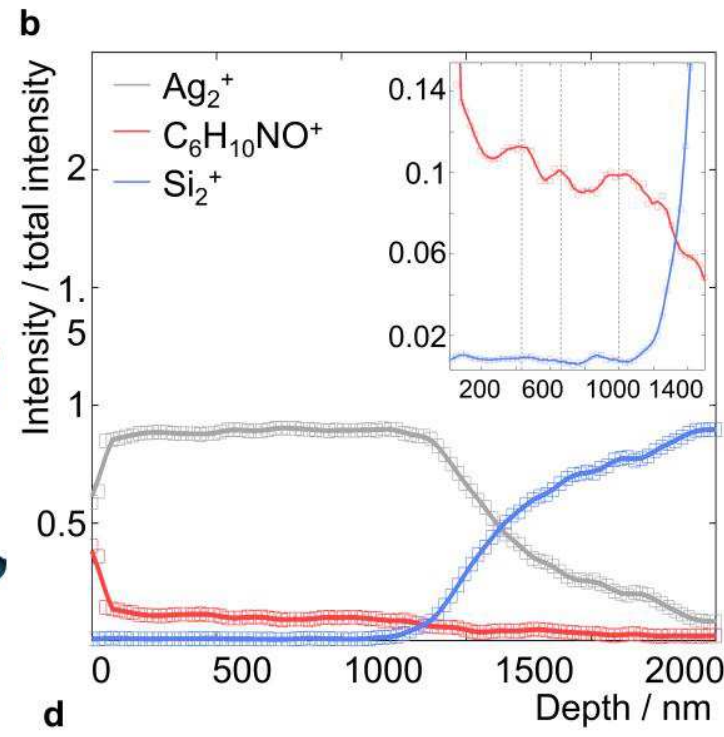

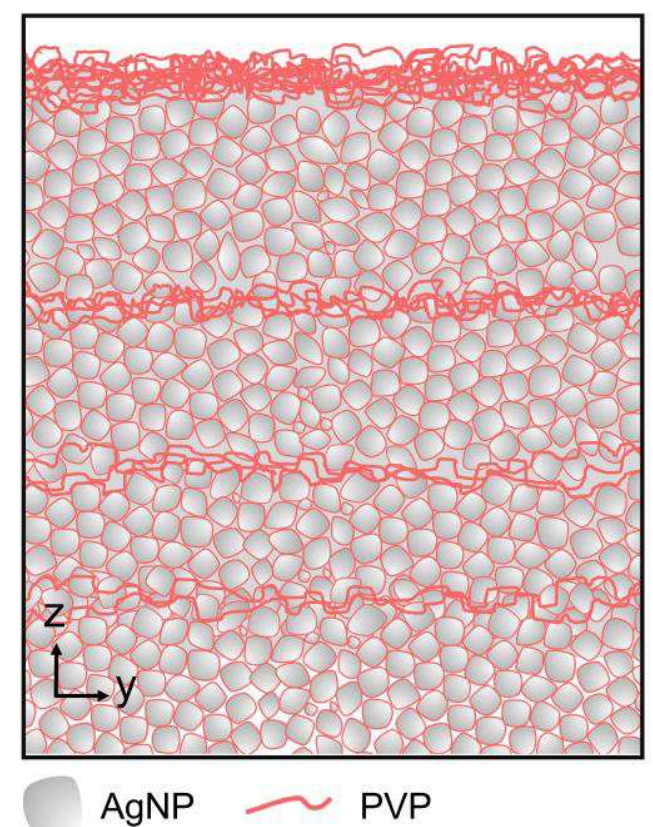

Fig. 2 3D chemical analysis of 4 stacked layers of inkjet 3D printed AgNPs. a 3D rendering of ToF-SIMS signal for $\mathrm{Ag}_{2}{ }^{+}, \mathrm{C}_{6} \mathrm{H}_{10} \mathrm{NO}^{+}$and $\mathrm{Si}^{+}$. b Depth profile (averaged over an area of $50 \times 50$ $\mu \mathrm{m}^{2}$ per depth level) showing accumulation of PVP at layers interface. c XPS N1s data for noninteracting, free (C-N, $400 \mathrm{eV}$ ) and interacting (C-N-Ag, $398 \mathrm{eV})$ PVP with the Ag surface on top surface and bulk ( 100 nm deep).d Illustration of cross-section of stacked AgNPs layers with PVP-rich interfaces.

The high resolution XPS spectrum of N1s of the printed AgNPs (Fig. 2c) shows that the non-interacting form of PVP, presumably unbound PVP residues in the ink, (represented 
by $\mathrm{C}-\mathrm{N}$ at $400 \mathrm{eV}$ ) is more abundant at the top surface, whilst the interacting form (represented by C-N-Ag at $398 \mathrm{eV}$ ) has a stronger signal in the bulk ( 100 nm deep). ${ }^{60}$ This, in conjunction with the ToF-SIMS depth profile (Fig. 2b), indicates that non or weakly-interacting PVP tends to migrate to the outer surface of the ink, forming a thin coating on the top surface upon solvent evaporation (Fig. 2d). However, non or weakly interacting PVP was also detected in between printed layers with relatively high intensity. In order to obtain enhanced depth resolution of chemical information within the printed material, we carried out ToF-SIMS depth profiling using a lower beam energy and lower current for the etching ion beam (Fig. 3) (details in Methods). Principal component analysis (PCA) using depth levels as observations and a list of peaks as variables (Fig. 3b-c PC 2 with $20.43 \%$ of total variance - full PCA results are in Supplementary Fig. S4) revealed a secondary, more complex, oscillating pattern within a single printed layer with an average period of $80.7 \mathrm{~nm}$ (confirmed by fast Fourier transforms in Supplementary Fig. S5b), which is compatible with the average diameter of individual silver nanoparticles in the ink $(60 \pm 22 \mathrm{~nm}$, Supplementary Fig. S3). The slightly higher length is attributed to nanoparticles packing and the oscillating pattern alternates between characteristic ions for silver (such as $\mathrm{Ag}^{+},{ }^{109} \mathrm{Ag}^{+}$and $\mathrm{Ag}_{2}{ }^{+}$) and PVP (such as $\mathrm{C}_{4} \mathrm{H}_{6} \mathrm{NO}^{+}$and $\mathrm{C}_{6} \mathrm{H}_{10} \mathrm{NO}^{+}$). We interpret that this is related to the core-shell structure of AgNPs/PVP and the irregularities in the signal arise from the average PVP distribution on the surface of several $\mathrm{Ag}$ nanoparticles within the ToF-SIMS analysis area.

In this nanoparticle-resolution depth profile, we tracked the signal of more specific secondary ions related to the cyclic amide of pyrrolidone $\left(\mathrm{C}_{6} \mathrm{H}_{10} \mathrm{NO}^{+}\right)$, linear hydrocarbon $\left(\mathrm{C}_{4} \mathrm{H}_{7}+\right)$, the cyclic amide-silver $\left(\mathrm{C}_{4} \mathrm{H}_{6} \mathrm{NOAg}^{+}\right)$and silver $\left(\mathrm{Ag}^{+}\right)$and normalised their signals by their maximum intensity (Fig. 3d-e). We observed that each ion signal peaks at different depths, revealing molecular-level information. These results give evidence of the interaction of PVP with the AgNPs surface (Fig. 3a), in agreement with what has been previously predicted via molecular dynamics simulations ${ }^{61-64}$. Every data point in the ToFSIMS depth profile represents only the first few nanometres of that depth level.; moreover, none of the secondary ion intensities decrease to zero within an oscillation, which is related to the fact that the capping polymer is present on the surface of all silver nanoparticles. 
a
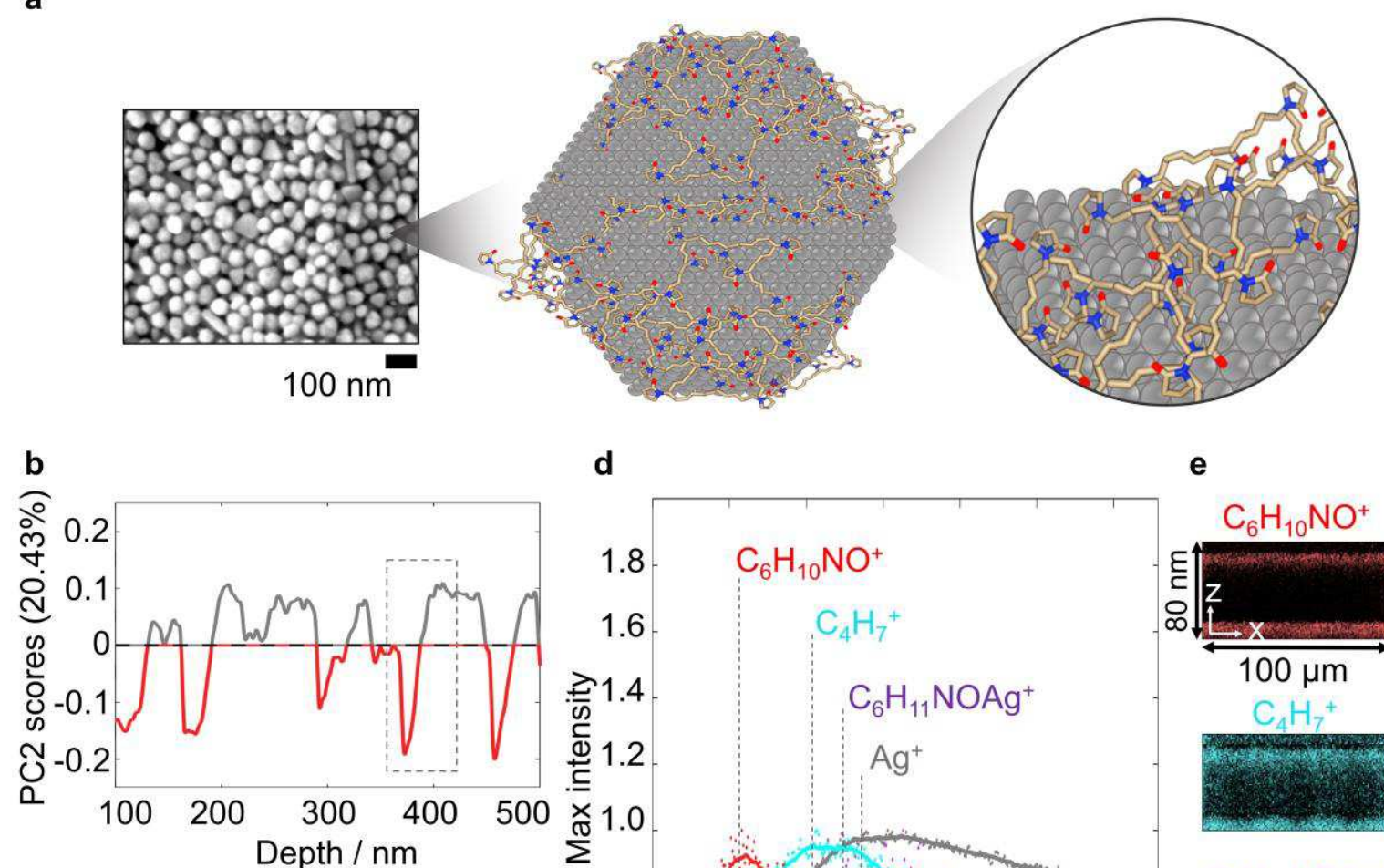

d

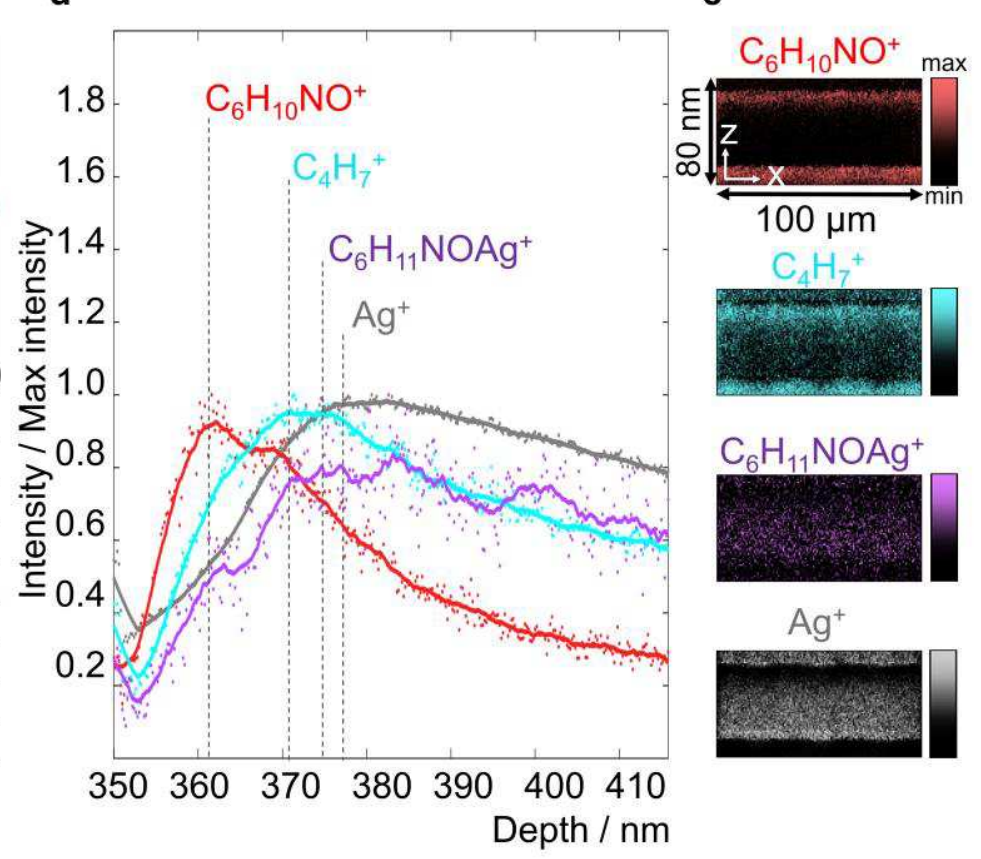

Fig. 3 PVP coordination onto AgNPs surface. A SEM micrograph of printed AgNPs and schematic showing PVP coordination on a single AgNP surface. $\mathbf{b}$ PCA scores and $\mathbf{c}$ loadings of depth profiling data at nanoparticle depth resolution. The dashed rectangle represents $\mathbf{d}$ depth profile within $100 \mathrm{~nm}$ showing signals for secondary ions $\mathrm{C}_{6} \mathrm{H}_{10} \mathrm{NO}^{+}, \mathrm{C}_{4} \mathrm{H}_{7}^{+}, \mathrm{C}_{6} \mathrm{H}_{11} \mathrm{NOAg}^{+}$and $\mathrm{Ag}^{+}$. e XZ maps within a depth of $80 \mathrm{~nm}$. The data is averaged over an area of $100 \times 100 \mu \mathrm{m}^{2}$ per depth level.

Influence of sintering temperature on the distribution of residual polymer stabiliser and electrical resistivity 
Sintering is a commonly used post process to promote inter-particulate bridging as well as the removal of residual organics. To evaluate how this process affects chemical, morphological and electrical properties of printed samples, the AgNPs were deposited and pinned as both single-layer and 200 layers electrodes and post-processed in an oven at different temperatures $(T)$ up to $500{ }^{\circ} \mathrm{C}$. The resistivity of all samples was measured at room temperature (Fig. 4a,b,d), while their morphology was assessed by electron microscopy (Fig. 4c and Supplementary Fig. S6). The planar resistivity $\left(\rho_{x y}\right)$ of the sample with a single printed layer decreased dramatically after processing at $100{ }^{\circ} \mathrm{C}$ and the resistivity remains $\sim 13 \mu \Omega \cdot \mathrm{cm}$ for the samples sintered at the temperatures ranging from $100{ }^{\circ} \mathrm{C}$ to $200{ }^{\circ} \mathrm{C}$. Micrographs of AgNPs show that the particles start bridging around these temperatures (Fig. 4c.i,ii), hence forming conductive channels and leading to resistivity reduction. We noticed that $\rho_{x y}$ of the single layer printed AgNP samples remains about one order of magnitude higher than expected for bulk silver (black dashed line in Fig. 4d). A further increase of processing temperature to above $300{ }^{\circ} \mathrm{C}$ results in an unexpected increase of $\rho_{x y}$ for the single-layered samples due to inter-particle voids with diameters between 200 and $500 \mathrm{~nm}$ shown in Fig. 4c.iii. When the AgNPs were processed at $500^{\circ} \mathrm{C}$, the AgNPs agglomerated into macro structures sized 1 to $5 \mu \mathrm{m}$ with very poor continuity (Fig. 4c.iv). For multi-layer samples (200 layers), the stacking of layers filled the voids and thus avoided the deterioration of conductivity pathways to keep the planer resistivity in the range of 10 $\mu \Omega \cdot \mathrm{cm}$ for all samples treated at high temperatures to $500^{\circ} \mathrm{C}$. However, the vertical resistivity of 200 layers $\left(\rho_{z}\right)$ is about up to three orders of magnitude higher $(23560 \pm 8350$ $\mu \Omega \cdot \mathrm{cm}$ for samples treated at $T=130^{\circ} \mathrm{C}$ ) than $\rho_{x y}$. We employed XPS and ToF-SIMS to detect residual PVP at the surface of printed AgNPs after processing (Fig. 4e-h). The results show that PVP is still present after sintering the printed samples at temperatures between 100 and $230^{\circ} \mathrm{C}$, where resistivity is heavily anisotropic. Moreover, the proportion of non-interacting PVP (normalised ratio between XPS N1s peaks at $400 \mathrm{eV}$ and $398 \mathrm{eV}$, Fig. 4e) increases with processing temperatures at the top surface but decreases in the bulk ( 100nm deep). This confirms the hypothesis that weakly interacting PVP migrates to the surface (or layer interface in multi-layer samples) during sintering. These results also agree with thermal gravimetric analysis results that show a $70 \%$ weight loss between 
the temperatures of $150^{\circ} \mathrm{C}$ and $250{ }^{\circ} \mathrm{C}$, from solvent evaporation (available in Supplementary, Fig. S7).

a Planar resistivity

b Vertical resistivity

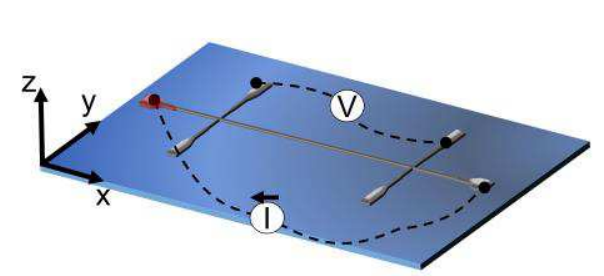

Si wafer AgNPs

PEN film with hole

Ag paste Glass slide

ITO ‥-•Wires

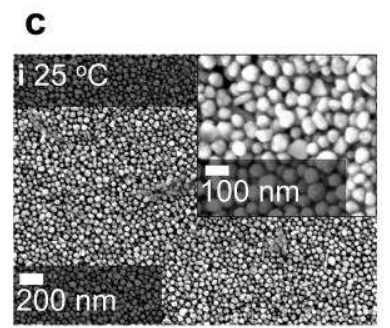

d

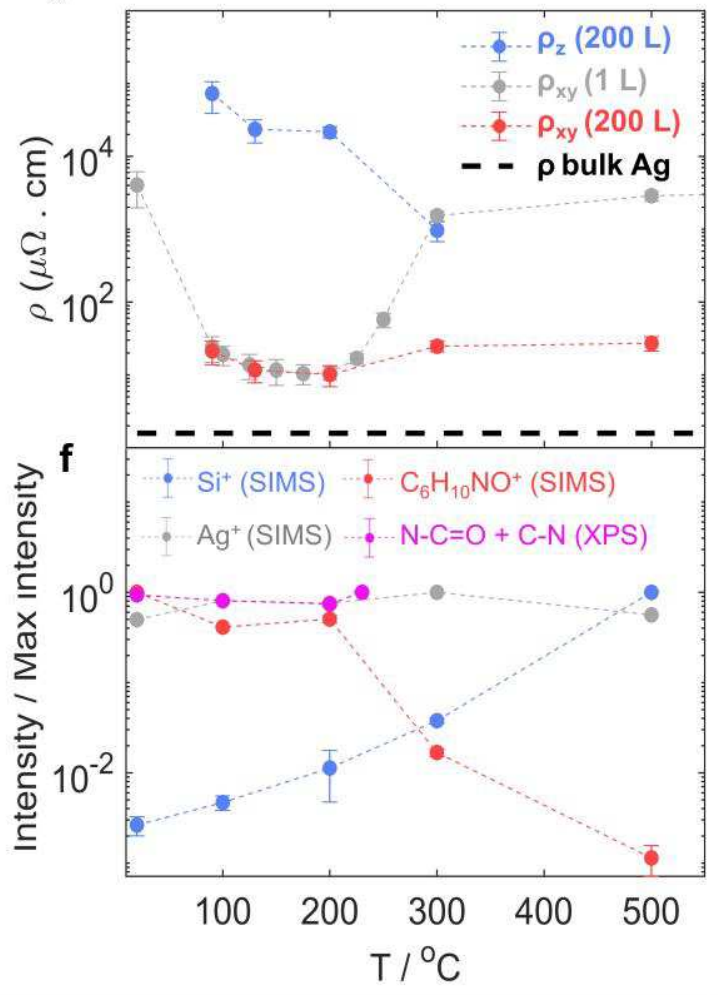

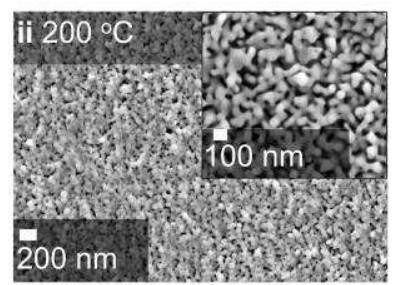

e

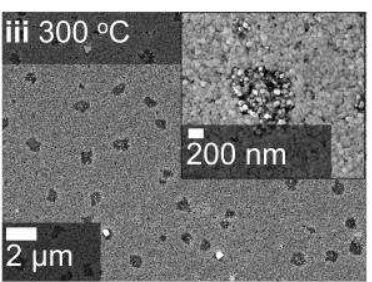

$\%$ of non-interacting PVP
$2300^{\circ} \mathrm{C}$

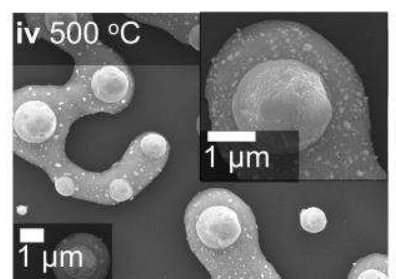

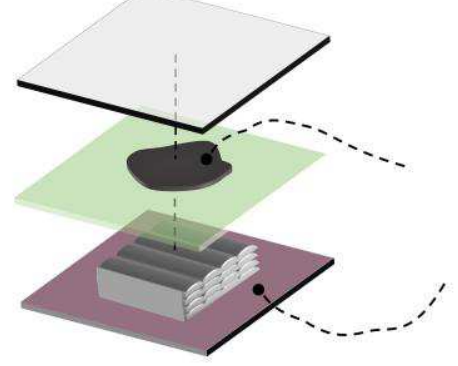
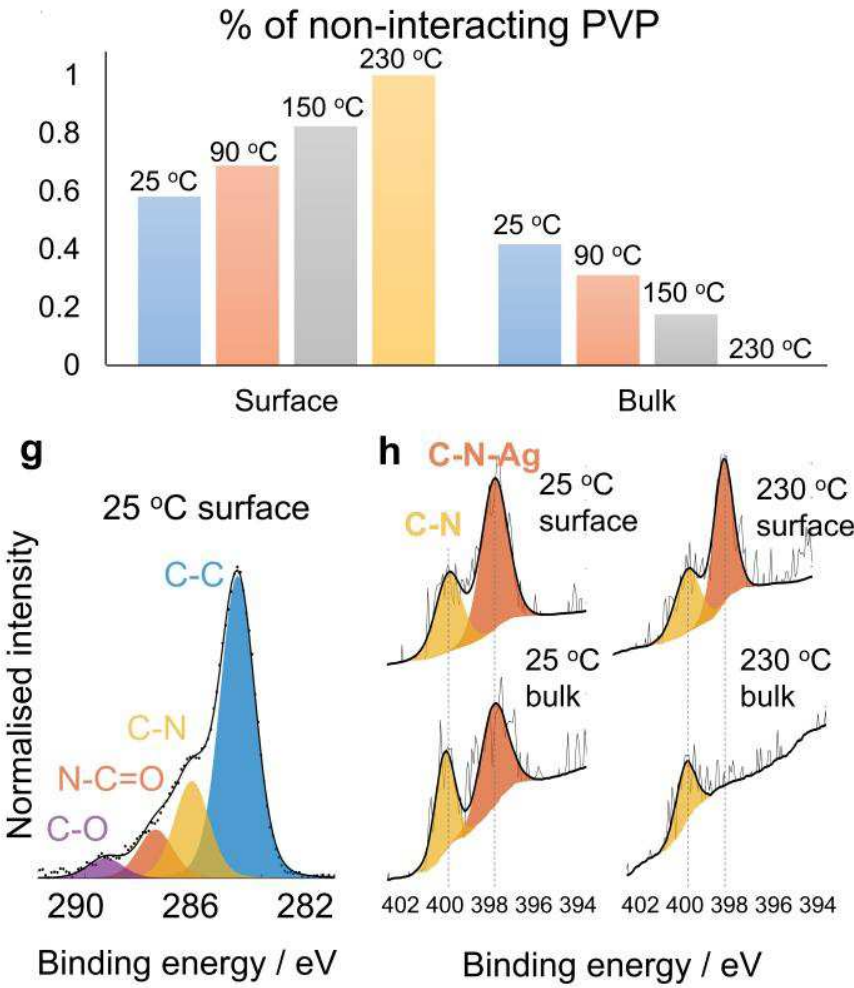

Fig. 4 Surface analysis, resistivity, and morphology of AgNPs printed and sintered at different temperatures. Schematic of $\mathbf{a}$ single layer and $\mathbf{b}$ multi-layer inkjet printed AgNPs 
electrodes for planar and vertical resistivity measurements. c Secondary electron micrographs of electrodes sintered at different temperatures: i. $25^{\circ} \mathrm{C}$, ii. $200^{\circ} \mathrm{C}$, iii. $300^{\circ} \mathrm{C}$ and iv. $500^{\circ} \mathrm{C}$. d Results of planar $\left(\rho_{x y}\right)$ and vertical $\left(\rho_{x y}\right)$ resistivity tests for single-layer and 200-layers samples sintered at different temperatures. e Percentage of non-interacting PVP (from XPS) at the surface and bulk for samples treated at different temperatures. $\mathbf{f}$ Characteristic ToF-SIMS secondary ions for PVP $\left(\mathrm{C}_{6} \mathrm{H}_{10} \mathrm{NO}^{+}\right)$, silver $\left(\mathrm{Ag}^{+}\right)$and the substrate $\left(\mathrm{Si}^{+}\right)$and $X P S \mathrm{C}_{1 s}$ peak-fitted ${ }^{52}$ components $\mathrm{N}$ $\mathrm{C}=\mathrm{O}+\mathrm{C}-\mathrm{N}$ in function of sintering temperature. $\mathrm{g}$ XPS C1s peak fitting for sample at $25^{\circ} \mathrm{C}$ and h XPS N1s peak fitting for samples at $25^{\circ} \mathrm{C}$ and $230^{\circ} \mathrm{C}$. Details of the XPS peak-fitting parameters can be found in Supplementary Tables ST1 and ST2.

\section{Residual PVP in a multi-material 3D printed device}

We applied the same methodology to map residual PVP within a fully 3D printed encapsulated strain sensor that was produced via multi-material inkjet printing (Fig. 5ab). The conductive channel consists of 5 printed layers of AgNPs processed using UV light and the dielectric material is tri(propylene glycol)diacrylate (TPGDA), represented by the secondary ion $\mathrm{C}_{3} \mathrm{H}_{3} \mathrm{O}^{+}$. Details about the device and printing method are reported in our previous work. ${ }^{4,43}$ As both the dielectric and conductive layers are printed contemporaneously, temperatures for in-situ or post-processing must remain low to avoid damaging the organic material. Moreover, the glass transition temperature $\left(T_{g}\right)$ of PVP is in the range $100 \sim 150{ }^{\circ} \mathrm{C}$, depending on its molecular weight ${ }^{55,65,66}$, which may lead to migration of PVP within the surface and interface of AgNPs during the post-processing sintering. ${ }^{67}$ Chemical depth profiling results (Fig. 5c,e) show that residual PVP is present at higher quantities at the dielectric/conductive materials interface, in agreement with the results shown in Fig. 2, where greater signal of PVP was detected at the top surface of AgNPs printed layers. The presence of organic residues at the interface between contemporaneously deposited materials is potentially deleterious to device performance where, specifically for this case, it may influence adhesion between the organic and inorganic materials. Furthermore, at the top TPGDA/AgNPs interface (Fig. 5c), silver is detected earlier in the depth profile than PVP. This is explained by TEM micrographs of a cross section of the device (Fig. $\mathbf{5 d}$ ), which show interpenetration of AgNPs into the dielectric material. This is not observed at the bottom interface (Fig. 5e) because of the 
order in which materials are deposited: AgNPs deposited on a solidified layer of organic material have less mobility than when a liquid organic material is deposited onto a layer of AgNPs.

a
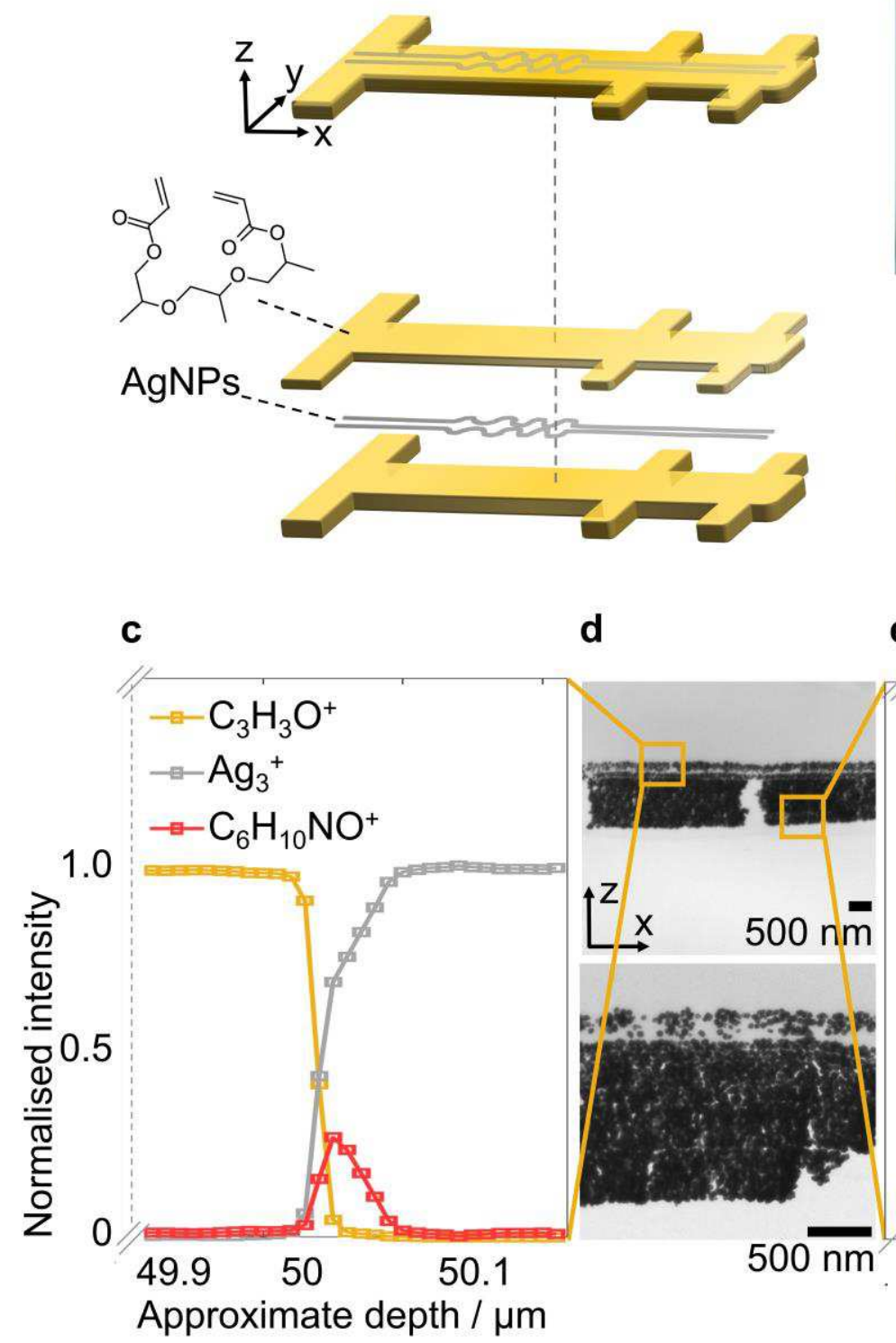

b
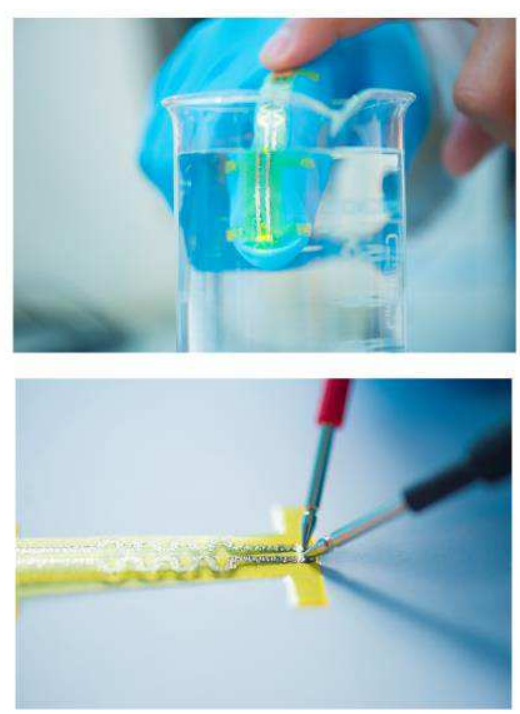

e

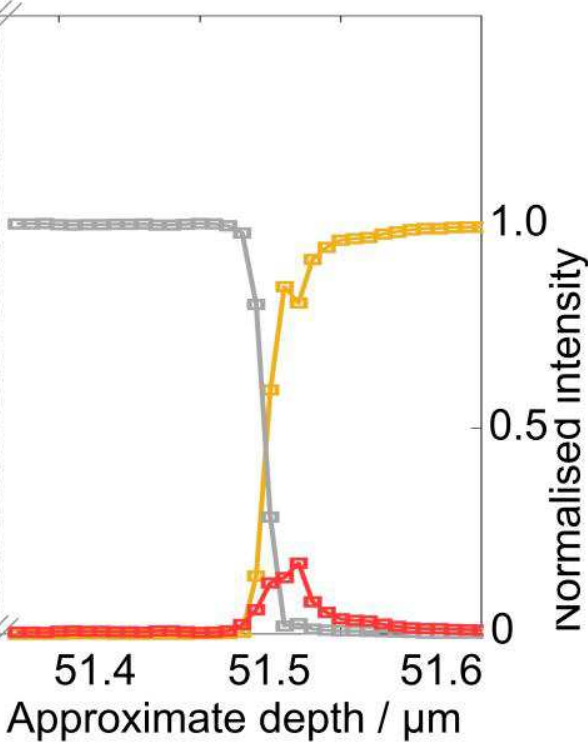

Fig. 5 Presence of residual stabiliser in a multi-material inkjet 3D printed encapsulated strain sensor. a Schematic showing the layer structure of the device. b photographs showing that encapsulation enables the use of the device under water. ToF-SIMS depth profile results at 
the c top and e bottom interface. The dielectric material is TPGDA and represented by $\mathrm{C}_{3} \mathrm{H}_{3} \mathrm{O}^{+}$. PVP is represented by $\mathrm{C}_{6} \mathrm{H}_{10} \mathrm{NO}^{+} \mathbf{d}$ TEM micrographs of a cross section.

\section{Discussion}

We showed that poor inter and intra-layer electrical conductivity in silver structures produced via 3D inkjet printing of AgNPs results from a combined chemistry and morphology interface evolution during the low-temperature sintering process. This has been achieved via the determination of the 3D spatial distribution of residual polymeric capping agents within multiple printed layers. The residual polymer leads to anisotropic conductivity reduction as we showed that such organic residues accumulate at the interface of vertically stacked printed layers. With a clearer understanding of the distribution of residual organic stabiliser within the printed layers, it is possible to consider optimisation strategies to overcome the functional anisotropy of inkjet-based 3D printed electronics. When printing multiple layers, it is not practical to remove the part from the printer after each layer, especially when multiple materials are deposited contemporaneously (Fig. 5). In that case, post-processing strategies should be converted into in-situ processing steps. When working with commercially available nanoparticulate ink formulations, the presence of a polymer stabiliser such as PVP is often inevitable, which therefore requires additional post processing methods to overcome functional anisotropy. We showed that higher sintering temperatures are not always beneficial, not only because of potential damage to the substrate or contemporaneously deposited materials, but also because AgNPs tend to coalesce, resulting in further planar conductivity reduction. Silver nanoparticles have been proven to be sintered with ultraviolet (UV) and infrared (IR) light, which makes it the most likely processing route for printing 3D macrostructures, ${ }^{4,30}$ therefore, the understanding of how a stabiliser behaves upon printing and sintering of metal nanoparticles is essential to aid ink formulation routes with different stabilisers that can either be removed at lower temperatures or be breakable upon excitation using UV or IR sources. ${ }^{68}$

\section{Methods}


AgNPs ink used in this work was purchased from Advanced Nano Products (SilverJet DGP-40LT-15C) and was used as-received. The nominal composition of the ink consists of $38.85 \mathrm{wt} \%$ of silver nanoparticles dispersed in triethylene glycol monomethyl ether (TGME) and other additives. Thermogravimetry analysis (TGA) and differential scanning calorimetry (DSC) of silver NP inks were performed simultaneously on a TA Q600 unit. The sample ink was placed and dried in a vacuum oven at $40{ }^{\circ} \mathrm{C}$ prior to the measurement. The sample was heated up at a temperature ramp of $10^{\circ} \mathrm{C} \mathrm{min}^{-1}$ under constant nitrogen flow of $100 \mathrm{mlmin}^{-1}$.

AgNPs samples were printed using a Fujifilm Dimatix Materials Printer DMP-2850 Series with a $10 \mathrm{pL}$ cartridge. The droplet diameter is $\sim 45 \mu \mathrm{m}$ and a drop spacing distance of $30 \mu \mathrm{m}$ was used to ensure deposition of continuous layers and pattern uniformity. Only one nozzle was employed to maximise the morphological homogeneity and geometrical precision of deposition. The samples were printed on a $\mathrm{Si} / \mathrm{SiO}_{2}$ substrate. For all samples (apart of room temperature sample) the substrate was heated to $90{ }^{\circ} \mathrm{C}$ by an in-situ resistance heater.

The encapsulated strain sensor was inkjet 3D printed with co-deposition of the AgNPs and an organic ink made in-house and based on tri(propylene glycol)diacrylate (TPGDA). Both polymer and silver layers were printed and cured/sintered contemporaneously by a LED-based UV source connected to the print-heads of a PixDro LP50 printer. This sample was used to benchmark a sample preparation methodology previously published. ${ }^{43}$ More details of the ink formulations and printing method are described elsewhere. ${ }^{4}$

The planar resistivity of printed AgNPs samples was measured using a Keithley 2400 sourcemeter and a Keithley 7500 multimeter with a four-probe method, also known as Kelvin technique, to eliminate contact resistance. A voltage is applied from the two probes at the ends and the current through the printed line was measured with the change of voltage drop across the two probes in the middle. Each $I-V$ curve was measured three times using both forward and backwards scanning. The derivative of the $I-V$ curve reveals the conductivity of the printed line with the precise geometry measured by an optical microscope. All measurements were repeated three times for at least three different samples, and results are presented as an average value with its standard deviation. 
The vertical resistivity of multiple printed layers of AgNPs was measured by printing two hundred layers of the silver nanoparticle ink on ITO glass at $90^{\circ} \mathrm{C}$ for good drying and pinning and sintering at $130^{\circ} \mathrm{C}, 200^{\circ} \mathrm{C}$ and $300^{\circ} \mathrm{C}$. A $125 \mu \mathrm{m}$ thick PEN film with a window of the same size and shape of the sample was put on top to expose the top layers and insulate the bottom contacts from the top contact. A glass slide with a wire and dried silver paste facing downwards are then pushed firmly on top of the sample and the PEN film as the top contact. The I-V curve is then measured using a Keithly sourcemeter to extract the resistance. From all measurements, we could still observe a contact resistance for all samples. To work out the contact resistance, the same procedures have been repeated for 50 printed layers. The sample thicknesses were measured by SEM of cross sections. By subtracting the resistance of thinner samples, the $\rho_{z}$ values of different sintering temperatures can be obtained.

Scanning electron microscopy (SEM) was carried out using a JEOL 7100F FEGSEM instrument which uses an in-lens Schottky field emission source. The microscope was operated a with a $5 \mathrm{keV}$ electron beam and at a working distance of $5 \mathrm{~mm}$. Samples were mounted on an aluminium stub using double-sided conductive carbon tape. Image analysis was done with ImageJ $1.49 \mathrm{k}$.

Transmission electron microscopy (TEM) was carried out using a JEOL 2000 FX TEM with a $200 \mathrm{kV}$ electron beam. Thin cross-sections of the encapsulated strain sensor were prepared using a diamond knife in an Ultramicrotome PowerTome (RMC Products). Samples were embedded in epoxy resin before cutting.

X-rays photoelectron spectroscopy (XPS) was carried out using an AXIS ULTRA instrument (Kratos) with a monochromated Al ka X-ray source $(1486.6 \mathrm{eV})$ operated at 10 $\mathrm{mA}$ emission current and $12 \mathrm{kV}$ anode potential (120 W) Spectra were acquired with the Kratos VISION II software. A charge neutraliser filament was used to prevent surface charging. High-resolution spectra at pass energy $20 \mathrm{eV}$, a step of $0.1 \mathrm{eV}$, and sweep times of 10 minutes each were also acquired for photoelectron peaks from the detected elements and these were used to model the chemical composition. All spectra were charge corrected to the $\mathrm{C}$ 1s peak (adventitious carbon / $\mathrm{CH}_{2}$ ) set to $284.8 \mathrm{eV}$. Peak fitting of the C1s and N1s scans was performed on the Casa XPS software (www.casaxps.com) 
using mixed Gaussian/Lorenzian components. Details of the fitting parameters are in

\section{Supplementary Tables ST1 and ST2.}

Surface time-of-flight secondary ion mass spectrometry (ToF-SIMS) of AgNPs samples treated at different temperatures was carried out using a ToF-SIMS IV instrument (IONTOF GmbH). Secondary ion mass spectra were acquired in positive ion polarity mode using a $25 \mathrm{keV} \mathrm{Bi}_{3}{ }^{+}$primary ion beam delivering $0.3 \mathrm{pA}$. The primary ion beam was raster scanned over different areas with the total ion dose kept under the static limit of $10^{13}$ ions $/ \mathrm{cm}^{2}$. The ToF analyser was set with $200 \mu$ s cycle time, resulting in a mass range between 0 and 3492 mass units and a low-energy $(20 \mathrm{eV})$ electron flood gun employed to neutralise charge build up.

ToF-SIMS 3D mapping of AgNPs was carried out using a 3D OrbiSIMS (Hybrid SIMS) instrument from IONTOF GmbH. The ToF-SIMS data were acquired in positive ion polarity mode in dual-beam mode by raster scanning a $30 \mathrm{keV} \mathrm{Bi}_{3}{ }^{+}$primary ion beam (delivering $0.08 \mathrm{pA}$ ) of $100 \times 100 \mu \mathrm{m}^{2}$ at the centre of a $300 \times 300 \mu \mathrm{m}^{2}$ sputter crater formed using an argon gas cluster ion beam (GCIB). The GCIB was operated in two conditions, high-energy with $20 \mathrm{keV}$ and 2000 atoms in the cluster with $5 \mathrm{nA}$ beam current and low energy using $10 \mathrm{keV}$ and 1500 atoms per cluster delivering $3 \mathrm{nA}$. The analysis was performed in the "non-interlaced" mode with a low-energy (20 eV) electron flood gun employed to neutralise charge build up. For the low-energy settings, 3 sputter frames were performed per cycle with 15 analysis scans per cycle and a pause time in between cycles of $0.5 \mathrm{~s}$. For the high-energy settings, 5 sputter frames were performed per cycle with 20 analysis scans per cycle and a pause time in between cycles of $0.5 \mathrm{~s}$. The ToF analyser was set with $200 \mu$ s cycle time, resulting in a mass range between 0 and 2233 mass units.

ToF-SIMS depth profiling of multi-material device: was carried out using a ToFSIMS IV (IONTOF GmbH) in dual-beam mode by raster scanning a $25 \mathrm{keV} \mathrm{Bi}^{+}$primary ion beam (delivering $0.08 \mathrm{pA}$ ) of $100 \times 100 \mu \mathrm{m}^{2}$ at the centre of a $300 \times 300 \mu \mathrm{m}^{2}$ sputter

crater formed using a $20 \mathrm{keV}$ argon gas cluster ion beam (GCIB) delivering $20 \mathrm{nA}$. The analysis was performed in the "non-interlaced" mode with a low-energy $(20 \mathrm{eV})$ electron flood gun employed to neutralise charge build up. 5 sputter frames were performed per cycle with 20 analysis scans per cycle and a pause time in between cycles of $0.5 \mathrm{~s}$. The 
ToF analyser was set with $200 \mu$ s cycle time, resulting in a mass range between 0 and 2233 mass units. AgNPs/TPGDA interfaces were reached profiling from top and bottom surfaces. To reach the buried interfaces, the etching beam current had to be greater and acquisition time per level lower, which resulted respectively in limited depth resolution and lower signal to noise ratio to be able to detect PVP within layers of AgNPs in a similar manner to what is presented in Fig. 1 and Fig. 2).

ToF-SIMS data processing: All ToF-SIMS intensity maps were normalised by total ion counts to correct for topographic features. All intensity maps were produced using the simsMVA software. ${ }^{69}$ For 3D renders, voxel intensities were normalised by total ion counts to account for topographic features and the z-scale was corrected based on the substrate signal. The final 3D representations were created by combining rendered isosurfaces ranging from $30 \%$ to $50 \%$ of the maximum intensity for each ion. Multivariate analysis was carried out using the mass as the variables and each spectrum in the depth profile sequence as the observations. For each depth profiling dataset, Surface Lab 7.1 (IONTOF $\mathrm{GmbH}$ ) was used to perform an automated peak search on the total spectra restricted only to peaks with intensity higher than 100 counts and masses between $30 \mathrm{u}$ and $300 \mathrm{u}$. Dead-time corrected peak areas were then exported for each sequential mass spectrum in the depth profile. Principal component analysis (PCA) was performed using the simsMVA software, ${ }^{69}$ which yields components loadings with groups of peaks that shared the same depth profile (scores). Prior to PCA, data was Poisson scaled to account for heteroscedasticity. ${ }^{70}$

Orbitrap secondary ion mass spectrometry (OrbiSIMS) was carried out using a 3D OrbiSIMS (Hybrid SIMS) instrument. ${ }^{53}$ A $20 \mathrm{keV} \mathrm{Ar} 3000^{+}$GCIB of $20 \mu \mathrm{m}$ diameter, delivering $3.5 \mathrm{nA}$ (with duty cycle set to $70.4 \%$ ) was used as the primary ion beam. Depth profiling data were acquired over areas of $300 \times 300 \mu \mathrm{m}^{2}$ using random raster mode with crater size $382 \times 382 \mu \mathrm{m}^{2}$. The sample voltage was set at $+57.5 \mathrm{~V}$. Argon gas flooding was used to aid charge compensation and the pressure in the main chamber was maintained at $9.0 \times 10^{-7}$ bar. The spectra were collected in positive polarity, in mass range $50-750 \mathrm{~m} / \mathrm{z}$. Mass resolving power was 218,726 at $200 \mathrm{~m} / \mathrm{z}$.

Optical profilometry was used to determine the crater depth after ToF-SIMS depth profiling experiments and calibrate the depth scale. Scans were obtained using a Zeta- 
20 optical microscope (Zeta Instruments) in a $Z$ range of $4.6 \mu \mathrm{m}$. The number of steps was set to 328 , allowing for a $z$ step size of $14 \mathrm{~nm}$.

\section{Acknowledgements}

This work was funded by the Engineering and Physical Sciences Research Council award: "Enabling Next Generation Additive Manufacturing" (grant number EP/P031684/1). The authors acknowledge access to facilities at the Nanoscale and Microscale Research Centre (nmRC) of the University of Nottingham and technical support from Dr Emily Smith (XPS measurements), Ms Nichola Weston (assistance with ultra-microtome and TEM) and Mr Martin Roe (assistance with the electron microscopy). The EPSRC are gratefully acknowledged for the Strategic Equipment grant "3D OrbiSIMS: Label free chemical imaging of materials, cells and tissues" funding that supported this work (grant no. EP/P029868/1).

\section{Authors contributions}

GFT, FW, YH, CJT, RH and CJR conceived and planned the experiments. GFT carried out the chemical characterisation, data analysis and interpretation supported by $\mathbf{Y H}, \mathbf{J l}$, DS, IG, MT, LT, RW, RH and CJR. GFT, AB and DP carried out electron microscopy. FW, YH and AB produced all AgNPs samples. DP carried out the thermogravimetry analysis. ES designed and produced the encapsulated strain sensor supported by CJT. FW carried out the resistivity tests supported by $\mathbf{J I}$, LT and CJT. All authors provided critical feedback and wrote the manuscript.

\section{References}

(1) Kamyshny, A.; Magdassi, S. Conductive Nanomaterials for 2D and 3D Printed Flexible Electronics. Chem. Soc. Rev. 2019, 48 (6), 1712-1740. https://doi.org/10.1039/c8cs00738a.

(2) Ko, S. H.; Pan, H.; Grigoropoulos, C. P.; Luscombe, C. K.; Fréchet, J. M. J.; 
Poulikakos, D. All-Inkjet-Printed Flexible Electronics Fabrication on a Polymer Substrate by Low-Temperature High-Resolution Selective Laser Sintering of Metal Nanoparticles. Nanotechnology 2007, 18 (34). https://doi.org/10.1088/09574484/18/34/345202.

(3) Lewis, J. A.; Ahn, B. Y. Three-Dimensional Printed Electronics. Nature 2015, 518, $42-43$.

(4) Saleh, E.; Zhang, F.; He, Y.; Vaithilingam, J.; Fernandez, J. L.; Wildman, R.; Ashcroft, I.; Hague, R.; Dickens, P.; Tuck, C. 3D Inkjet Printing of Electronics Using UV Conversion. Adv. Mater. Technol. 2017, 2 (10), 2-9. https://doi.org/10.1002/admt.201700134.

(5) Vaithilingam, J.; Simonelli, M.; Saleh, E.; Senin, N.; Wildman, R. D.; Hague, R. J. M.; Leach, R. K.; Tuck, C. J. Combined Inkjet Printing and Infrared Sintering of Silver Nanoparticles Using a Swathe-by-Swathe and Layer-by-Layer Approach for 3-Dimensional Structures. ACS Appl. Mater. Interfaces 2017, 9 (7), 6560-6570. https://doi.org/10.1021/acsami.6b14787.

(6) Begines, B.; Alcudia, A.; Aguilera-Velazquez, R.; Martinez, G.; He, Y.; Wildman, R.; Sayagues, M. J.; Jimenez-Ruiz, A.; Prado-Gotor, R. Design of Highly Stabilized Nanocomposite Inks Based on Biodegradable Polymer-Matrix and Gold Nanoparticles for Inkjet Printing. Sci. Rep. 2019, 9 (1), 1-12. https://doi.org/10.1038/s41598-019-52314-2.

(7) Zhang, F.; Saleh, E.; Vaithilingam, J.; Li, Y.; Tuck, C. J.; Hague, R. J. M.; Wildman, R. D.; He, Y. Reactive Material Jetting of Polyimide Insulators for Complex Circuit Board Design. Addit. Manuf. 2019, 25 (November 2018), 477-484. https://doi.org/10.1016/j.addma.2018.11.017.

(8) Fernandes, I. J.; Aroche, A. F.; Schuck, A.; Lamberty, P.; Peter, C. R.; Hasenkamp, W.; Rocha, T. L. A. C. Silver Nanoparticle Conductive Inks: Synthesis, Characterization, and Fabrication of Inkjet-Printed Flexible Electrodes. Sci. Rep. 2020, 10 (1), 1-11. https://doi.org/10.1038/s41598-020-65698-3. 
(9) Sasan, K.; Lange, A.; Yee, T. D.; Dudukovic, N.; Nguyen, D. T.; Johnson, M. A.; Herrera, O. D.; Yoo, J. H.; Sawvel, A. M.; Ellis, M. E.; Mah, C. M.; Ryerson, R.; Wong, L. L.; Suratwala, T.; Destino, J. F.; Dylla-Spears, R. Additive Manufacturing of Optical Quality Germania-Silica Glasses. ACS Appl. Mater. Interfaces 2020, 12 (5), 6736-6741. https://doi.org/10.1021/acsami.9b21136.

(10) Shi, L.; Meng, L.; Jiang, F.; Ge, Y.; Li, F.; Wu, X. gang; Zhong, H. In Situ Inkjet Printing Strategy for Fabricating Perovskite Quantum Dot Patterns. Adv. Funct. Mater. 2019, 29 (37), 1-6. https://doi.org/10.1002/adfm.201903648.

(11) Jeon, H.; Hong, S. K.; Kim, M. S.; Cho, S. J.; Lim, G. Omni-Purpose Stretchable Strain Sensor Based on a Highly Dense Nanocracking Structure for Whole-Body Motion Monitoring. ACS Appl. Mater. Interfaces 2017, 9 (48), 41712-41721. https://doi.org/10.1021/acsami.7b14153.

(12) Liu, S.; Yuen, M. C.; White, E. L.; Boley, J. W.; Deng, B.; Cheng, G. J.; KramerBottiglio, R. Laser Sintering of Liquid Metal Nanoparticles for Scalable Manufacturing of Soft and Flexible Electronics. ACS Appl. Mater. Interfaces 2018, 10 (33), 28232-28241. https://doi.org/10.1021/acsami.8b08722.

(13) Ko, S. H.; Pan, H.; Grigoropoulos, C. P.; Luscombe, C. K.; Fréchet, J. M. J.; Poulikakos, D. All-Inkjet-Printed Flexible Electronics Fabrication on a Polymer Substrate by Low-Temperature High-Resolution Selective Laser Sintering of Metal Nanoparticles. Nanotechnology 2007, 18 (34). https://doi.org/10.1088/09574484/18/34/345202.

(14) Tavakoli, M.; Malakooti, M. H.; Paisana, H.; Ohm, Y.; Green Marques, D.; Alhais Lopes, P.; Piedade, A. P.; de Almeida, A. T.; Majidi, C. EGaln-Assisted RoomTemperature Sintering of Silver Nanoparticles for Stretchable, Inkjet-Printed, ThinFilm Electronics. Adv. Mater. 2018, $30 \quad$ (29), 1-7. https://doi.org/10.1002/adma.201801852.

(15) Chen, S. P.; Kao, Z. K.; Lin, J. L.; Liao, Y. C. Silver Conductive Features on Flexible Substrates from a Thermally Accelerated Chain Reaction at Low Sintering 
Temperatures. ACS Appl. Mater. Interfaces 2012, 4 (12), 7064-7068. https://doi.org/10.1021/am302505j.

(16) Zhai, Q.; Yap, L. W.; Wang, R.; Gong, S.; Guo, Z.; Liu, Y.; Lyu, Q.; Wang, J.; Simon, G. P.; Cheng, W. Vertically Aligned Gold Nanowires as Stretchable and Wearable Epidermal Ion-Selective Electrode for Noninvasive Multiplexed Sweat Analysis. Anal. Chem. 2020. https://doi.org/10.1021/acs.analchem.0c00274.

(17) Zhang, F.; Saleh, E.; Vaithilingam, J.; Li, Y.; Tuck, C. J.; Hague, R. J. M.; Wildman, R. D.; He, Y. Reactive Material Jetting of Polyimide Insulators for Complex Circuit Board Design. Addit. Manuf. 2019, 25 (November 2018), 477-484. https://doi.org/10.1016/j.addma.2018.11.017.

(18) Carey, T.; Cacovich, S.; Divitini, G.; Ren, J.; Mansouri, A.; Kim, J. M.; Wang, C.; Ducati, C.; Sordan, R.; Torrisi, F. Fully Inkjet-Printed Two-Dimensional Material Field-Effect Heterojunctions for Wearable and Textile Electronics. Nat. Commun. 2017, 8 (1). https://doi.org/10.1038/s41467-017-01210-2.

(19) Zhang, S.; Cai, L.; Li, W.; Miao, J.; Wang, T.; Yeom, J.; Sepúlveda, N.; Wang, C. Fully Printed Silver-Nanoparticle-Based Strain Gauges with Record High Sensitivity. Adv. Electron. Mater. 2017, 3 (7), 1-6. https://doi.org/10.1002/aelm.201700067.

(20) Liu, Y.; Han, F.; Li, F.; Zhao, Y.; Chen, M.; Xu, Z.; Zheng, X.; Hu, H.; Yao, J.; Guo, T.; Lin, W.; Zheng, Y.; You, B.; Liu, P.; Li, Y.; Qian, L. Inkjet-Printed Unclonable Quantum Dot Fluorescent Anti-Counterfeiting Labels with Artificial Intelligence Authentication. Nat. Commun. 2019, 10 (1), 1-9. https://doi.org/10.1038/s41467019-10406-7.

(21) Kim, B. H.; Onses, M. S.; Lim, J. Bin; Nam, S.; Oh, N.; Kim, H.; Yu, K. J.; Lee, J. W.; Kim, J. H.; Kang, S. K.; Lee, C. H.; Lee, J.; Shin, J. H.; Kim, N. H.; Leal, C.; Shim, M.; Rogers, J. A. High-Resolution Patterns of Quantum Dots Formed by Electrohydrodynamic Jet Printing for Light-Emitting Diodes. Nano Lett. 2015, 15 (2), 969-973. https://doi.org/10.1021/nl503779e. 
(22) Hu, Z.; Yin, Y.; Ali, M. U.; Peng, W.; Zhang, S.; Li, D.; Zou, T.; Li, Y.; Jiao, S.; Chen, S. J.; Lee, C. Y.; Meng, H.; Zhou, H. Inkjet Printed Uniform Quantum Dots as Color Conversion Layers for Full-Color OLED Displays. Nanoscale 2020, 12 (3), 21032110. https://doi.org/10.1039/c9nr09086j.

(23) Li, T.; Pan, Y.; Wang, Z.; Xia, Y.; Chen, Y.; Huang, W. Additive Engineering for Highly Efficient Organic-Inorganic Halide Perovskite Solar Cells: Recent Advances and Perspectives. J. Mater. Chem. A 2017, 5 (25), 12602-12652. https://doi.org/10.1039/c7ta01798g.

(24) Huckaba, A. J.; Lee, Y.; Xia, R.; Paek, S.; Bassetto, V. C.; Oveisi, E.; Lesch, A.; Kinge, S.; Dyson, P. J.; Girault, H.; Nazeeruddin, M. K. Inkjet-Printed Mesoporous TiO 2 and Perovskite Layers for High Efficiency Perovskite Solar Cells. Energy Technol. 2019, 7 (2), 317-324. https://doi.org/10.1002/ente.201800905.

(25) Mathies, F.; List-Kratochvil, E. J. W.; Unger, E. L. Advances in Inkjet-Printed Metal Halide Perovskite Photovoltaic and Optoelectronic Devices. Energy Technol. 2019, 1900991. https://doi.org/10.1002/ente.201900991.

(26) Mathies, F.; Abzieher, T.; Hochstuhl, A.; Glaser, K.; Colsmann, A.; Paetzold, U. W.; Hernandez-Sosa, G.; Lemmer, U.; Quintilla, A. Multipass Inkjet Printed Planar Methylammonium Lead lodide Perovskite Solar Cells. J. Mater. Chem. A 2016, 4 (48), 19207-19213. https://doi.org/10.1039/c6ta07972e.

(27) Sowade, E.; Kang, H.; Mitra, K. Y.; Weiß, O. J.; Weber, J.; Baumann, R. R. Roll-toRoll Infrared (IR) Drying and Sintering of an Inkjet-Printed Silver Nanoparticle Ink within 1 Second. J. Mater. Chem. C 2015, 3 (45), 11815-11826. https://doi.org/10.1039/c5tc02291f.

(28) Niittynen, J.; Abbel, R.; Mäntysalo, M.; Perelaer, J.; Schubert, U. S.; Lupo, D. Alternative Sintering Methods Compared to Conventional Thermal Sintering for Inkjet Printed Silver Nanoparticle Ink. Thin Solid Films 2014, 556, 452-459. https://doi.org/10.1016/j.tsf.2014.02.001.

(29) Magdassi, S.; Grouchko, M.; Berezin, O.; Kamyshny, A. Triggering the Sintering of 
Silver Nanoparticles at Room Temperature. ACS Nano 2010, 4 (4), 1943-1948. https://doi.org/10.1021/nn901868t.

(30) Vaithilingam, J.; Saleh, E.; Körner, L.; Wildman, R. D.; Hague, R. J. M.; Leach, R. K.; Tuck, C. J. 3-Dimensional Inkjet Printing of Macro Structures from Silver Nanoparticles. Mater. Des. 2018, 139, 81-88. https://doi.org/10.1016/j.matdes.2017.10.070.

(31) Balliu, E.; Andersson, H.; Engholm, M.; Öhlund, T.; Nilsson, H. E.; Olin, H. Selective Laser Sintering of Inkjet-Printed Silver Nanoparticle Inks on Paper Substrates to Achieve Highly Conductive Patterns. Sci. Rep. 2018, 8 (1), 2-10. https://doi.org/10.1038/s41598-018-28684-4.

(32) Liu, S.; Yuen, M. C.; White, E. L.; Boley, J. W.; Deng, B.; Cheng, G. J.; Kramerbottiglio, R. Laser Sintering of Liquid Metal Nanoparticles for Scalable Manufacturing of Soft and Flexible Electronics. ACS Appl. Mater. Interfaces 2018, 10, 28232-28241. https://doi.org/10.1021/acsami.8b08722.

(33) Su, R.; Park, S. H.; Li, Z.; McAlpine, M. C. 3D Printed Electronic Materials and Devices. Robot. Syst. Auton. Platforms 2019, 309-334. https://doi.org/10.1016/b978-0-08-102260-3.00013-5.

(34) Mohapatra, P.; Shaw, S.; Mendivelso-Perez, D.; Bobbitt, J. M.; Silva, T. F.; Naab, F.; Yuan, B.; Tian, X.; Smith, E. A.; Cademartiri, L. Calcination Does Not Remove All Carbon from Colloidal Nanocrystal Assemblies. Nat. Commun. 2017, 8 (1). https://doi.org/10.1038/s41467-017-02267-9.

(35) Frosch, T.; Chan, K. L. A.; Wong, H. C.; Cabral, J. T.; Kazarian, S. G. Nondestructive Three-Dimensional Analysis of Layered Polymer Structures with Chemical Imaging. Langmuir 2010, 26 (24), 19027-19032. https://doi.org/10.1021/la103683h.

(36) Bailey, J.; Havelund, R.; Shard, A. G.; Gilmore, I. S.; Alexander, M. R.; Sharp, J. S.; Scurr, D. J. 3D ToF-SIMS Imaging of Polymer Multilayer Films Using Argon Cluster Sputter Depth Profiling. ACS Appl. Mater. Interfaces 2015, 7 (4), 2654- 
2659. https://doi.org/10.1021/am507663v.

(37) Taylor, M.; Scurr, D.; Lutolf, M.; Buttery, L.; Zelzer, M.; Alexander, M.; Taylor, M.; Scurr, D.; Buttery, L.; Zelzer, M.; Alexander, M. Cluster Sputter Depth Profiling 3D Chemical Characterization of Frozen Hydrated Hydrogels Using ToF-SIMS with Argon Cluster Sputter Depth Profiling. 2016, 301. https://doi.org/10.1116/1.4928209.

(38) Singh, A. V.; Jungnickel, H.; Leibrock, L.; Tentschert, J.; Reichardt, P.; Katz, A.; Laux, P.; Luch, A. ToF-SIMS 3D Imaging Unveils Important Insights on the Cellular Microenvironment during Biomineralization of Gold Nanostructures. Sci. Rep. 2020, 10 (1), 1-11. https://doi.org/10.1038/s41598-019-57136-w.

(39) Cristaudo, V.; Collette, S.; Poleunis, C.; Reniers, F.; Delcorte, A. Surface Analysis and Ultra-Shallow Molecular Depth-Profiling of Polyethylene Treated by an Atmospheric Ar-D<inf $>2</ I n f>0$ Post-Discharge. Plasma Process. Polym. 2015, 12 (9), 919-925. https://doi.org/10.1002/ppap.201400248.

(40) Cristaudo, V.; Collette, S.; Tuccitto, N.; Poleunis, C.; Melchiorre, L. C.; Licciardello, A.; Reniers, F.; Delcorte, A. Molecular Surface Analysis and Depth-Profiling of Polyethylene Modified by an Atmospheric Ar-D2O Post-Discharge. Plasma Process. Polym. 2016, 13 (11), 1104-1117. https://doi.org/10.1002/ppap.201600061.

(41) Mouhib, T.; Poleunis, C.; Wehbe, N.; Michels, J. J.; Galagan, Y.; Houssiau, L.; Bertrand, P.; Delcorte, A. Molecular Depth Profiling of Organic Photovoltaic Heterojunction Layers by ToF-SIMS: Comparative Evaluation of Three Sputtering Beams. Analyst 2013, 138 (22), 6801-6810. https://doi.org/10.1039/c3an01035j.

(42) Liu, Y.; Lorenz, M.; levlev, A. V; Ovchinnikova, O. S. Secondary Ion Mass Spectrometry (SIMS) for Chemical Characterization of Metal Halide Perovskites. Adv. Funct. Mater. 2020, 2002201, 2002201. https://doi.org/10.1002/adfm.202002201.

(43) Tiddia, M.; Mihara, I.; Seah, M. P.; Trindade, G. F.; Kollmer, F.; Roberts, C. J.; 
Hague, R.; Mula, G.; Gilmore, I. S.; Havelund, R. Chemical Imaging of Buried Interfaces in Organic-Inorganic Devices Using Focused Ion Beam-Time-of-FlightSecondary-Ion Mass Spectrometry. ACS Appl. Mater. Interfaces 2019, 11 (4), 4500-4506. https://doi.org/10.1021/acsami.8b15091.

(44) lida, S.; Carr, D. M.; Fisher, G. L.; Miyayama, T. Accurate and Reproducible InDepth Observation of Organic-Inorganic Hybrid Materials Using FIB-TOF-SIMS. J. Vac. Sci. Technol. B, Nanotechnol. Microelectron. Mater. Process. Meas. Phenom. 2018, 36 (3), 03F107. https://doi.org/10.1116/1.5013670.

(45) Yang, L.; Seah, M. P.; Gilmore, I. S.; Morris, R. J. H.; Dowsett, M. G.; Boarino, L.; Sparnacci, K.; Laus, M. Depth Profiling and Melting of Nanoparticles in Secondary Ion Mass Spectrometry (SIMS). J. Phys. Chem. C 2013, 117 (31), 16042-16052. https://doi.org/10.1021/jp4048538.

(46) Priebe, A.; Barnes, J. P.; Edwards, T. E. J.; Pethö, L.; Balogh, I.; Michler, J. 3D Imaging of Nanoparticles in an Inorganic Matrix Using TOF-SIMS Validated with STEM and EDX. Anal. Chem. 2019, 91 (18), 11834-11839. https://doi.org/10.1021/acs.analchem.9b02545.

(47) Nanoparticles, S.; Shard, A. G. A Straightforward Method For Interpreting XPS Data From Core -. 2012. https://doi.org/10.1021/jp305267d.

(48) Konarski, P.; Iwanejko, I.; Mierzejewska, A. SIMS Depth pro $\AA^{\circledR}$ Ling of Working Environment Nanoparticles. 2003, 204, 757-761.

(49) Tune, I.; Suzer, S.; Correa-Duarte, M. A.; Liz-Marzán, L. M. XPS Characterization of Au (Core)/SiO2 (Shell) Nanoparticles. J. Phys. Chem. B 2005, 109 (16), 75977600. https://doi.org/10.1021/jp050767j.

(50) Baer, D. R.; Gaspar, D. J.; Nachimuthu, P.; Techane, S. D.; Castner, D. G. Application of Surface Chemical Analysis Tools for Characterization of Nanoparticles. Anal. Bioanal. Chem. 2010, 396 (3), 983-1002. https://doi.org/10.1007/s00216-009-3360-1. 
(51) Baer, D. R.; Engelhard, M. H.; Johnson, G. E.; Laskin, J.; Lai, J.; Mueller, K.; Munusamy, P.; Thevuthasan, S.; Wang, H.; Washton, N.; Elder, A.; Baisch, B. L.; Karakoti, A.; Kuchibhatla, S. V. N. T.; Moon, D. Surface Characterization of Nanomaterials and Nanoparticles: Important Needs and Challenging Opportunities. J. Vac. Sci. Technol. A Vacuum, Surfaces, Film. 2013, 31 (5), 050820. https://doi.org/10.1116/1.4818423.

(52) Smith, E. F.; Counsell, J. D. P.; Bailey, J.; Sharp, J. S.; Alexander, M. R.; Shard, A. G.; Scurr, D. J. Sample Rotation Improves Gas Cluster Sputter Depth Profiling of Polymers. Surf. Interface Anal. 2017, 49 (10), 953-959. https://doi.org/10.1002/sia.6250.

(53) Passarelli, M. K.; Pirkl, A.; Moellers, R.; Grinfeld, D.; Kollmer, F.; Havelund, R.; Newman, C. F.; Marshall, P. S.; Arlinghaus, H.; Alexander, M. R.; West, A.; Horning, S.; Niehuis, E.; Makarov, A.; Dollery, C. T.; Gilmore, I. S. The 3D OrbiSIMS-LabelFree Metabolic Imaging with Subcellular Lateral Resolution and High MassResolving Power. Nat. Methods 2017, No. november, nmeth.4504. https://doi.org/10.1038/nmeth.4504.

(54) Kang, S. W.; Kang, Y. S. Silver Nanoparticles Stabilized by Crosslinked Poly(Vinyl Pyrrolidone) and Its Application for Facilitated Olefin Transport. J. Colloid Interface Sci. 2011, 353 (1), 83-86. https://doi.org/10.1016/j.jcis.2010.09.033.

(55) Koczkur, K. M.; Mourdikoudis, S.; Polavarapu, L.; Skrabalak, S. E. Polyvinylpyrrolidone (PVP) in Nanoparticle Synthesis. Dalt. Trans. 2015, 44 (41), 17883-17905. https://doi.org/10.1039/c5dt02964c.

(56) Koczkur, K. M.; Mourdikoudis, S.; Polavarapu, L.; Skrabalak, S. E. Polyvinylpyrrolidone (PVP) in Nanoparticle Synthesis. 2015, 17883-17905. https://doi.org/10.1039/c5dt02964c.

(57) Deegan, R. D.; Bakajin, O.; Dupont, T. F.; Huber, G.; Nagel, S. R.; Witten, T. A. Capillary Flow as the Cause of Ring Stains from Dried Liquid Drops. Nature 1997, 389 (23), 827-829. 
(58) Deegan, R. D.; Bakajin, O.; Dupont, T. F.; Huber, G.; Nagel, S. R.; Witten, T. A. Contact Line Deposits in an Evaporating Drop. Phys. Rev. E - Stat. Physics, Plasmas, Fluids, Relat. Interdiscip. Top. 2000, 62 (1 B), 756-765. https://doi.org/10.1103/PhysRevE.62.756.

(59) Hu, H.; Larson, R. G. Marangoni Effect Reverses Coffee-Ring Depositions. J. Phys. Chem. B 2006, 110 (14), 7090-7094. https://doi.org/10.1021/jp0609232.

(60) Xian, J.; Hua, Q.; Jiang, Z.; Ma, Y.; Huang, W. Size-Dependent Interaction of the Poly(N-Vinyl-2-Pyrrolidone) Capping Ligand with Pd Nanocrystals. Langmuir 2012, 28 (17), 6736-6741. https://doi.org/10.1021/la300786w.

(61) Mdluli, P. S.; Sosibo, N. M.; Mashazi, P. N.; Nyokong, T.; Tshikhudo, R. T.; Skepu, A.; Van Der Lingen, E. Selective Adsorption of PVP on the Surface of Silver Nanoparticles: A Molecular Dynamics Study. J. Mol. Struct. 2011, 1004 (1-3), 131137. https://doi.org/10.1016/j.molstruc.2011.07.049.

(62) Kyrychenko, A.; Korsun, O. M.; Gubin, I. I.; Kovalenko, S. M.; Kalugin, O. N. Atomistic Simulations of Coating of Silver Nanoparticles with Poly(Vinylpyrrolidone) Oligomers: Effect of Oligomer Chain Length. J. Phys. Chem. C 2015, 119 (14), 7888-7899. https://doi.org/10.1021/jp510369a.

(63) Rossi, L. M.; Fiorio, J. L.; Garcia, M. A. S.; Ferraz, C. P. The Role and Fate of Capping Ligands in Colloidally Prepared Metal Nanoparticle Catalysts. Dalt. Trans. 2018, 47 (17), 5889-5915. https://doi.org/10.1039/c7dt04728b.

(64) Safo, I. A.; Werheid, M.; Dosche, C.; Oezaslan, M. The Role of Polyvinylpyrrolidone (PVP) as a Capping and Structure-Directing Agent in the Formation of $\mathrm{Pt}$ Nanocubes. Nanoscale Adv. 2019, 1 (8), 3095-3106. https://doi.org/10.1039/c9na00186g.

(65) Knopp, M. M.; Olesen, N. E.; Holm, P.; Langguth, P.; Holm, R.; Rades, T. Influence of Polymer Molecular Weight on Drug-Polymer Solubility: A Comparison between Experimentally Determined Solubility in PVP and Prediction Derived from Solubility in Monomer. J. Pharm. Sci. 2015, 104 (9), 2905-2912. 
https://doi.org/10.1002/jps.24410.

(66) Alahmad, A.; Eleoui, M.; Falah, A.; Alghoraibi, I. Preparation of Colloidal Structural Characterization Silver Nanoparticles And. Phys. Sci. Res. Int. 2013, 1 (4), 89-96.

(67) Rossi, L. M.; Fiorio, J. L.; Garcia, M. A. S.; Ferraz, C. P.; Rossi, L. M. The Role and Fate of Capping Ligands in Colloidally Prepared Metal Nanoparticle Catalysts. 2018, 5889-5915. https://doi.org/10.1039/c7dt04728b.

(68) Black, K.; Singh, J.; Mehta, D.; Sung, S.; Sutcliffe, C. J.; Chalker, P. R. Silver Ink Formulations for Sinter-Free Printing of Conductive Films. Sci. Rep. 2016, 6 (January), 1-7. https://doi.org/10.1038/srep20814.

(69) Trindade, G. F.; Abel, M.; Watts, J. F. SimsMVA : A Tool for Multivariate Analysis of ToF- SIMS Datasets. Chemom. Intell. Lab. Syst. 2018. https://doi.org/10.1016/j.chemolab.2018.10.001.

(70) Keenan, M. R.; Smentkowski, V. S. The Statistics of ToF-SIMS Data Revisited and Introduction of the Empirical Poisson Correction. Surf. Interface Anal. 2016, 48 (4), 218-225. https://doi.org/10.1002/sia.5955. 


\section{Figures}

a

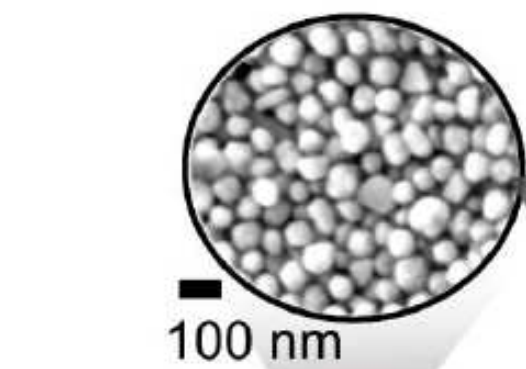

b

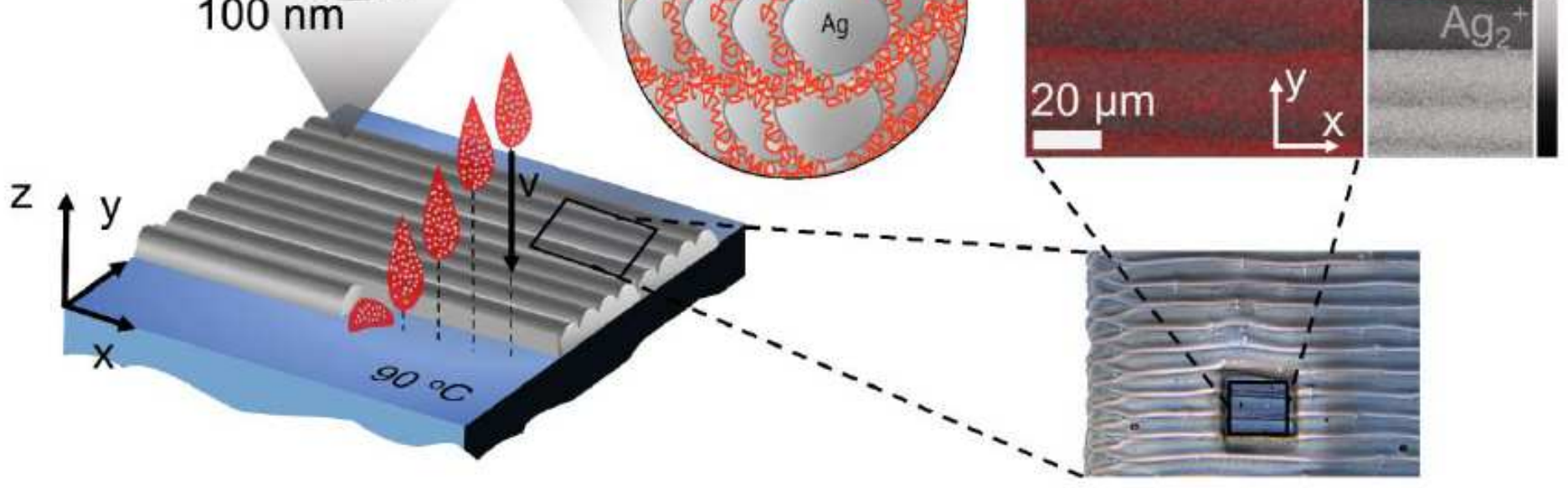

C

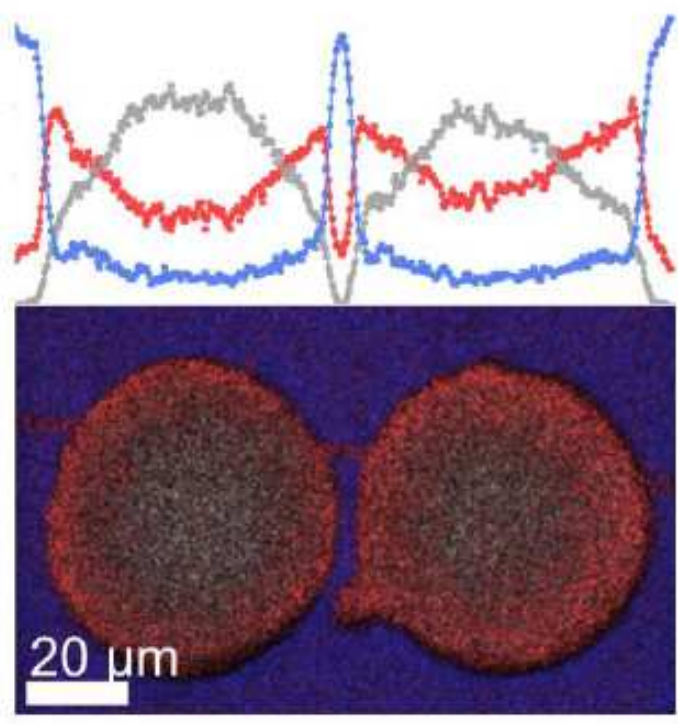

d
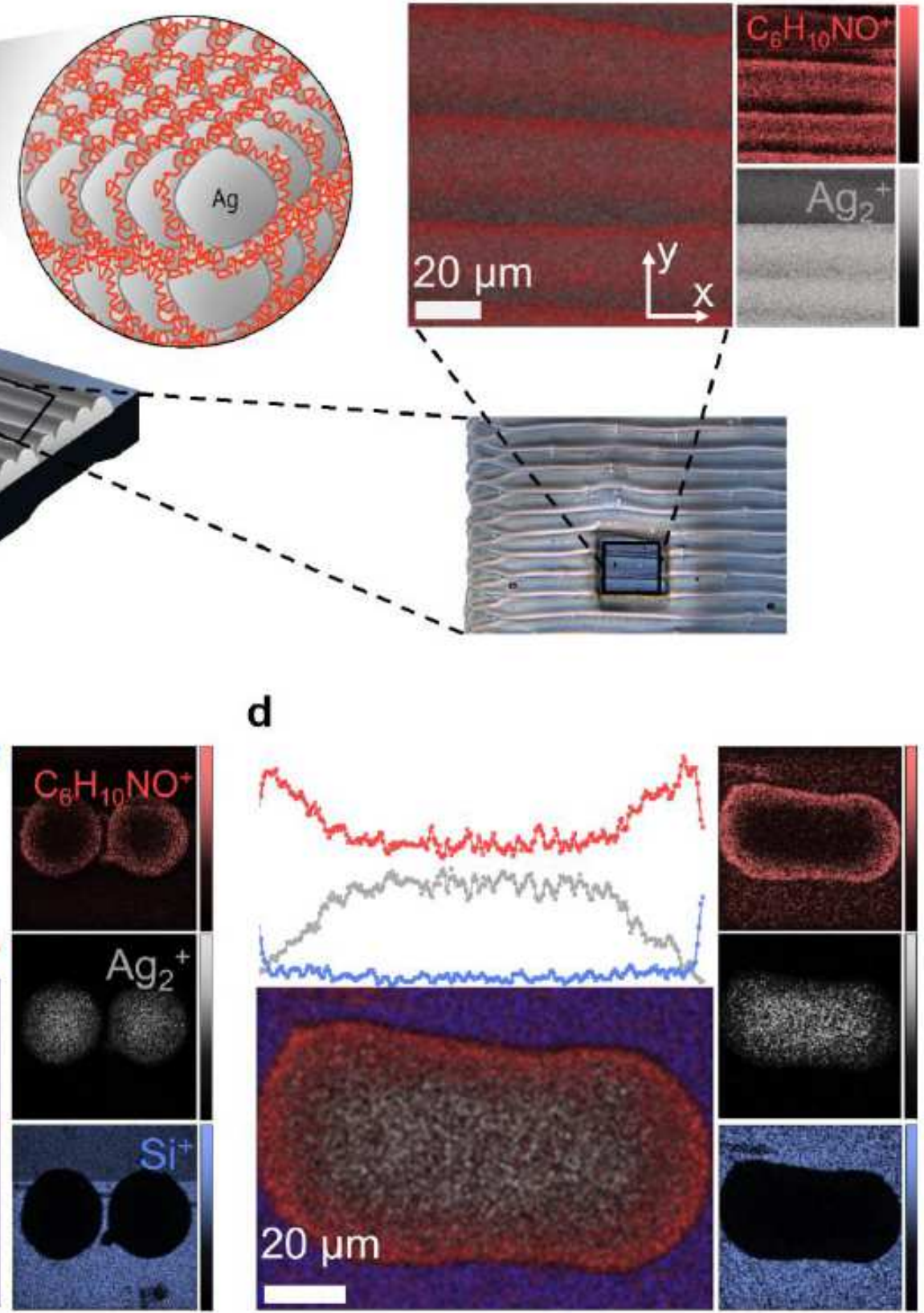

$\mathrm{Ag}_{2}$ 


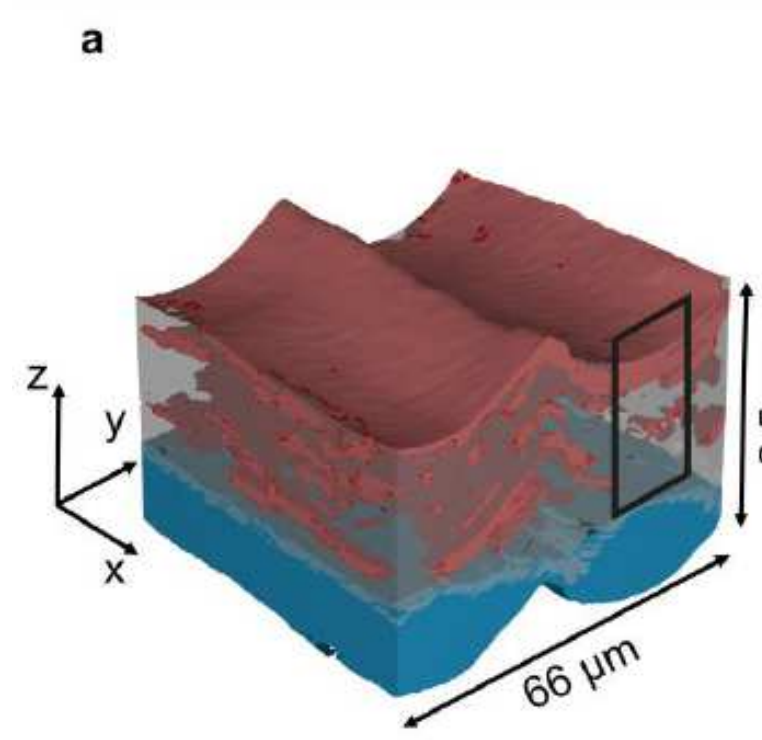

C

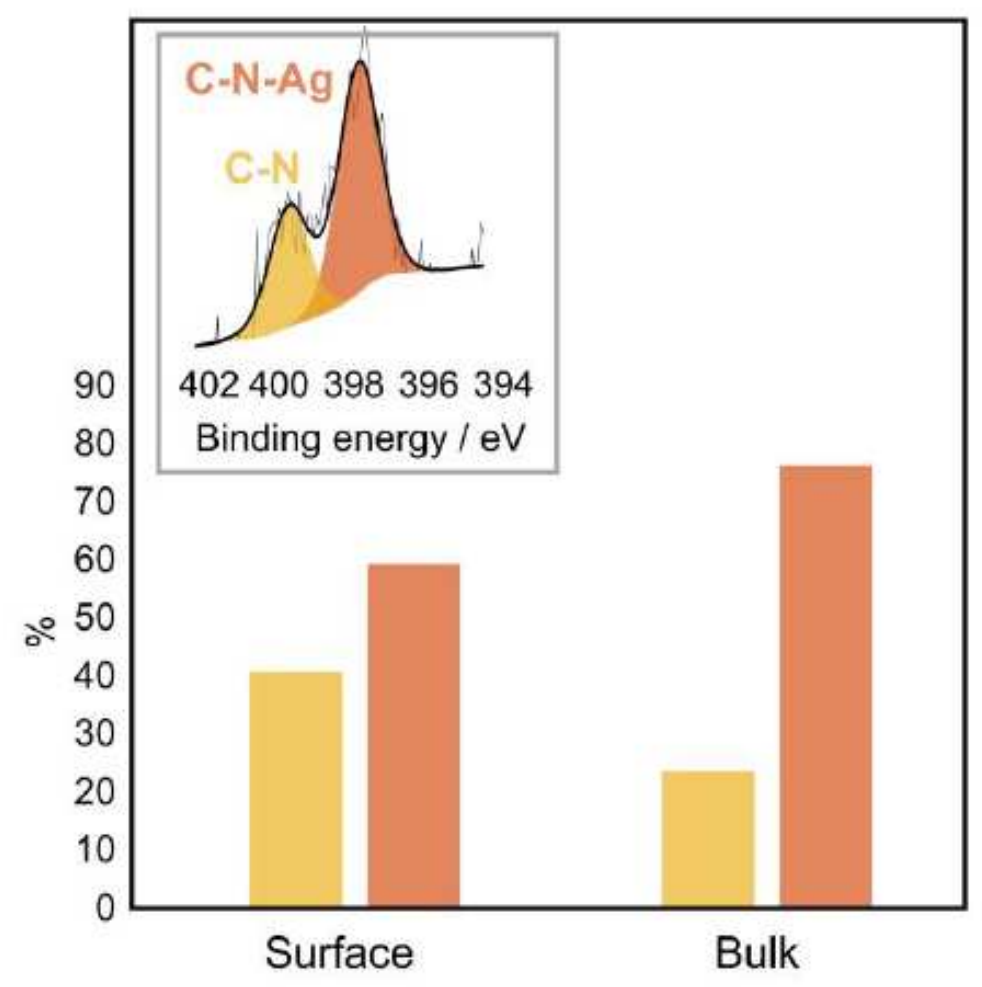

b
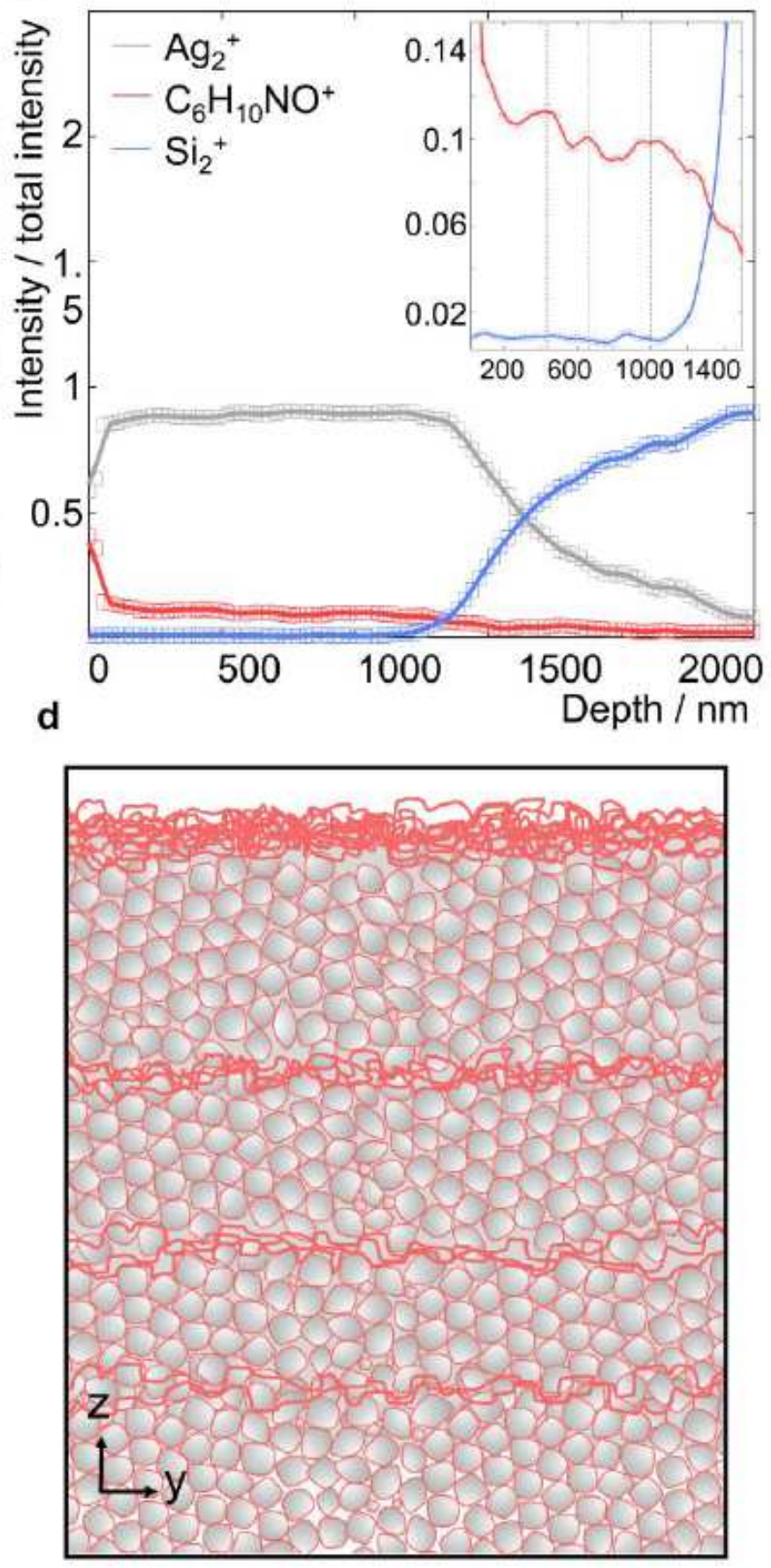

$\mathrm{AgNP} \sim \mathrm{PVP}$

\section{Figure 2}

3D chemical analysis of 4 stacked layers of inkjet 3D printed AgNPs. a 3D rendering of ToF-SIMS signal for Ag2+, $66 \mathrm{H} 10 \mathrm{NO}+$ and $\mathrm{Si}+$. b Depth profile (averaged over an area of $50 \times 50 \mu \mathrm{m} 2$ per depth level) showing accumulation of PVP at layers interface. c XPS N1s data for non-interacting, free (C-N, 400 eV) and interacting (C-N-Ag, $398 \mathrm{eV}$ ) PVP with the Ag surface on top surface and bulk ( 100 nm deep).d Illustration of cross-section of stacked AgNPs layers with PVP-rich interfaces. 
a
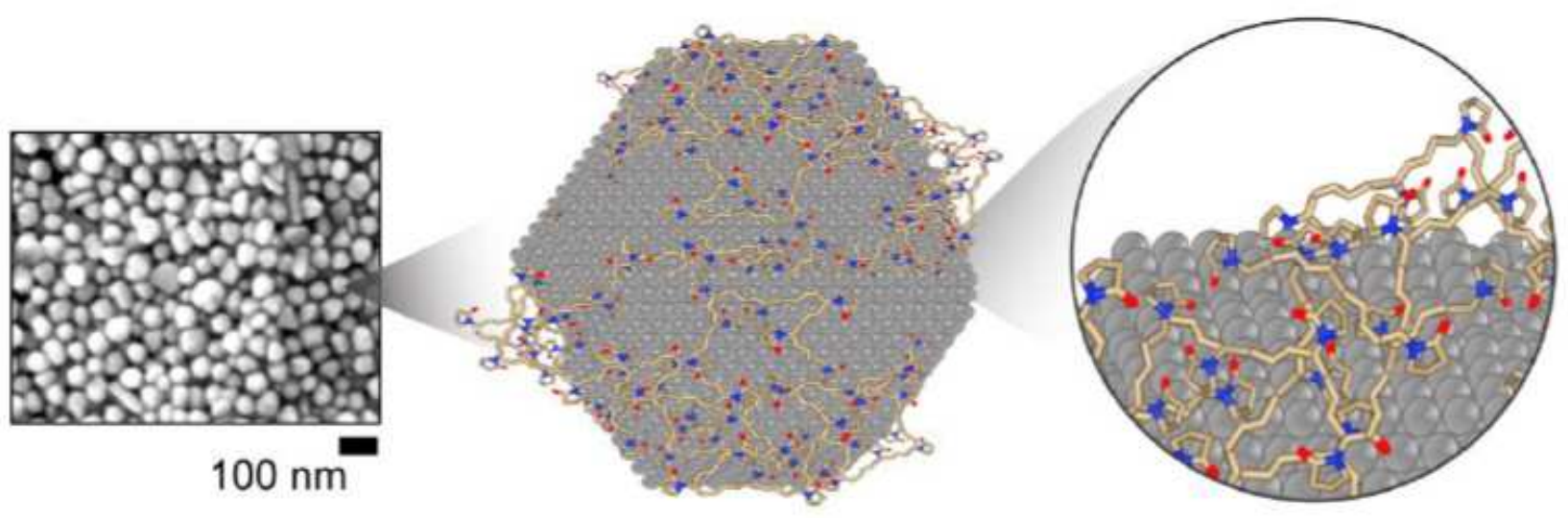

b
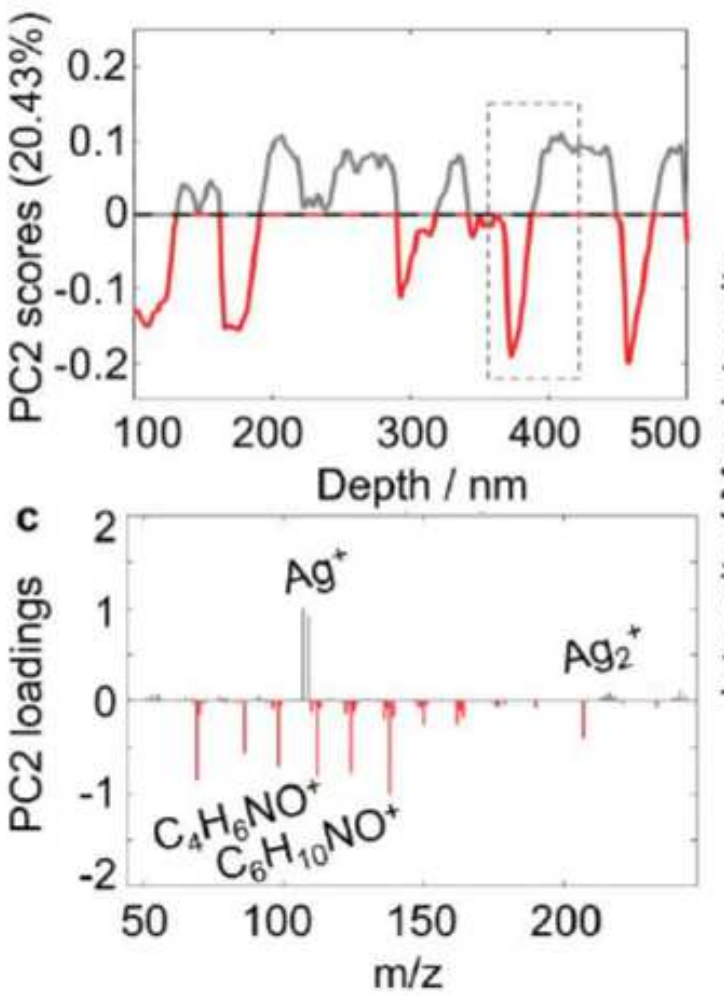

d

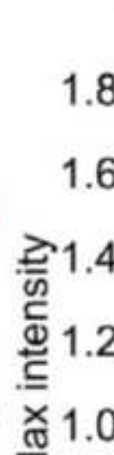

$\sum^{\pi}$

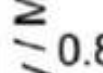

产

产 0 .

0.2
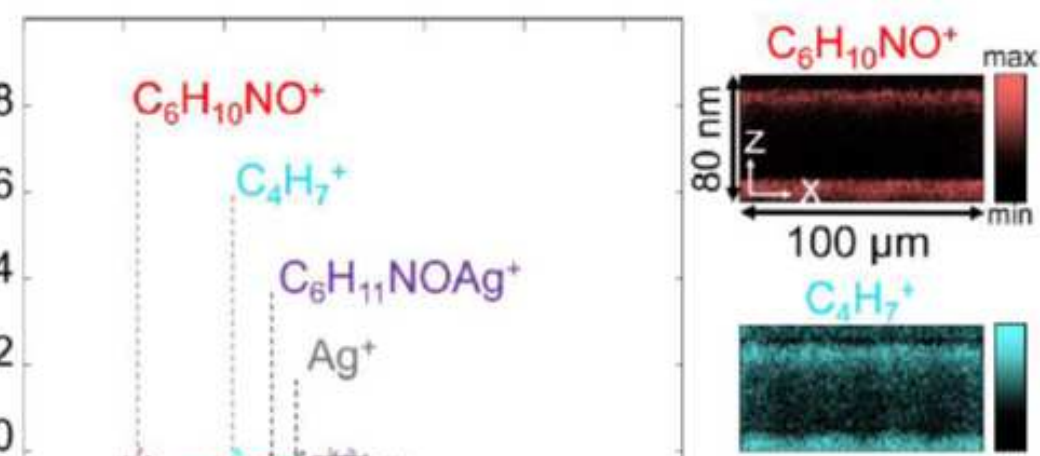

$\mathrm{C}_{6} \mathrm{H}_{11} \mathrm{NOAg}^{+}$

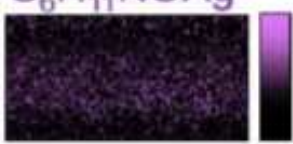

$\mathrm{Ag}^{+}$

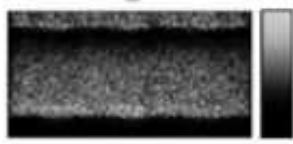

Depth / nm

\section{Figure 3}

PVP coordination onto AgNPs surface. A SEM micrograph of printed AgNPs and schematic showing PVP coordination on a single AgNP surface. b PCA scores and c loadings of depth profiling data at nanoparticle depth resolution. The dashed rectangle represents $\mathrm{d}$ depth profile within $100 \mathrm{~nm}$ showing signals for secondary ions $\mathrm{C} 6 \mathrm{H} 10 \mathrm{NO}+, \mathrm{C} 4 \mathrm{H} 7+, \mathrm{C} 6 \mathrm{H} 11 \mathrm{NOAg}+$ and Ag+. e XZ maps within a depth of 80 $\mathrm{nm}$. The data is averaged over an area of $100 \times 100 \mu \mathrm{m} 2$ per depth level. 


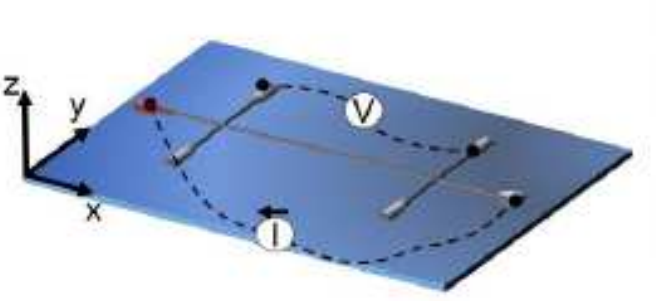

Si wafer $\mathrm{AgNPs}$

PEN film with hole

Ag paste Glass slide

ITO ‥ Wires

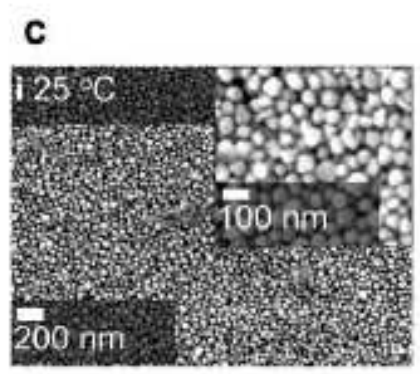

d

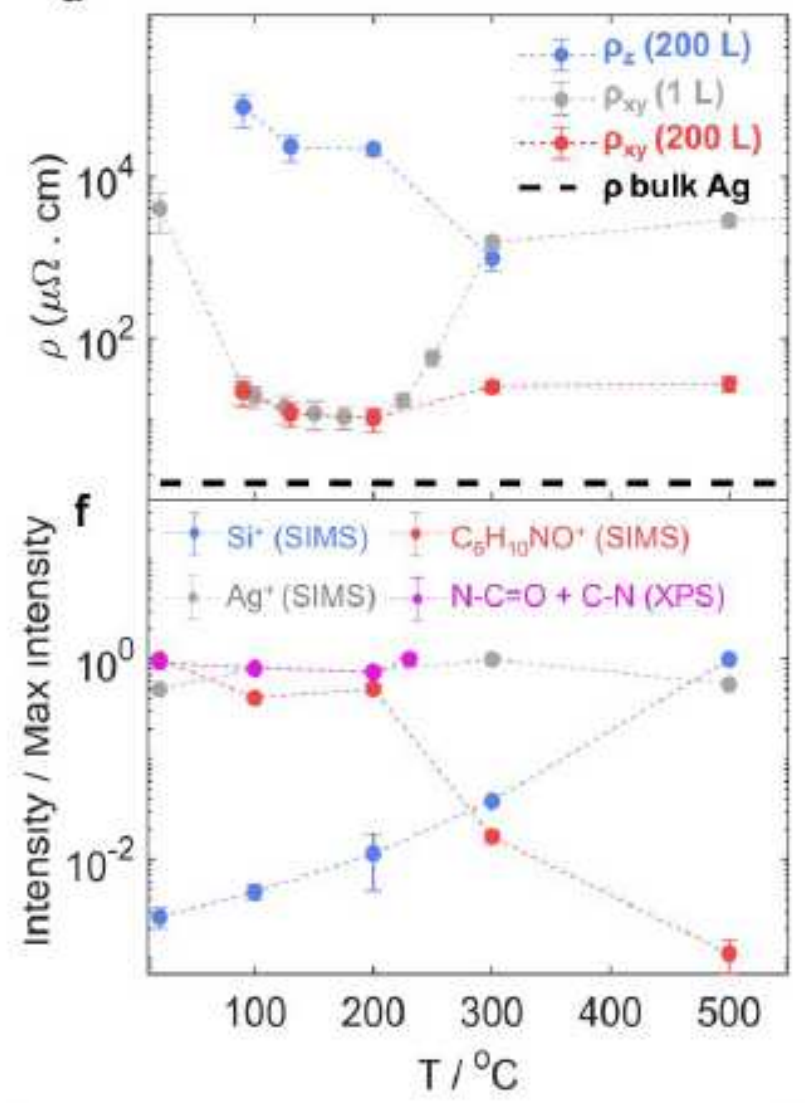

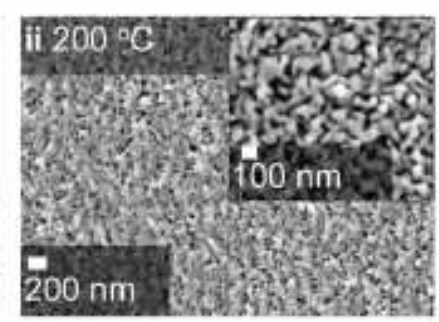

e
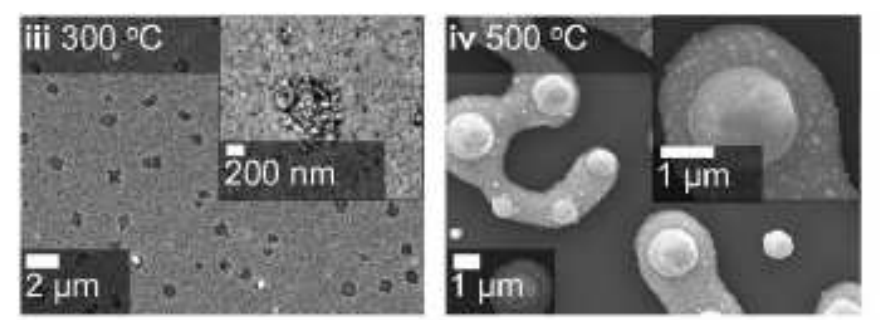

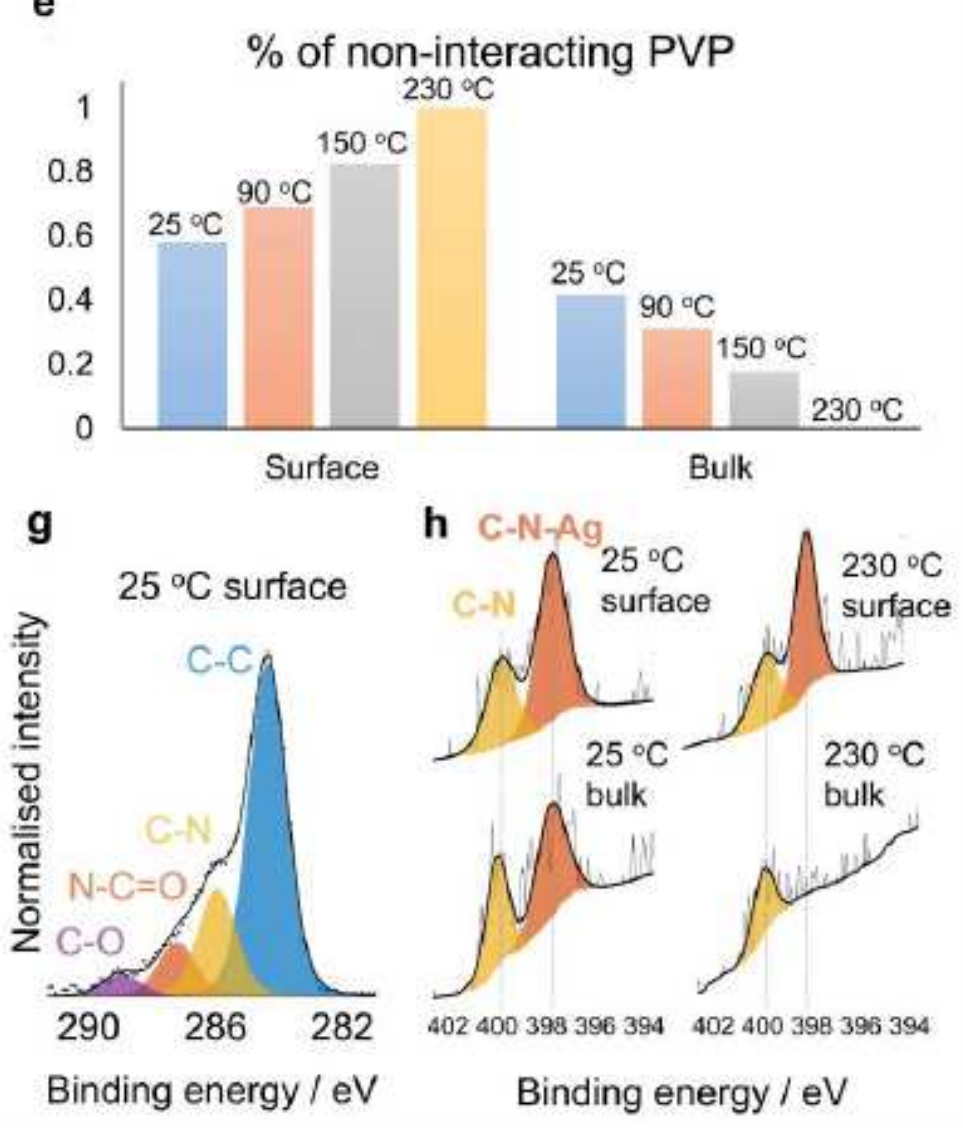

\section{Figure 4}

Surface analysis, resistivity, and morphology of AgNPs printed and sintered at different temperatures. Schematic of a single layer and b multi-layer inkjet printed AgNPs electrodes for planar and vertical resistivity measurements. c Secondary electron micrographs of electrodes sintered at different temperatures: i. $25^{\circ} \mathrm{C}$, ii. $200^{\circ} \mathrm{C}$, iii. $300^{\circ} \mathrm{C}$ and iv. $500^{\circ} \mathrm{C}$. d Results of planar ( $\left.\rho x y\right)$ and vertical ( $\left.\rho x y\right)$ resistivity tests for single-layer and 200-layers samples sintered at different temperatures. e Percentage of 
non-interacting PVP (from XPS) at the surface and bulk for samples treated at different temperatures. $f$ Characteristic ToF-SIMS secondary ions for PVP (C6H10NO+), silver (Ag+) and the substrate (Si+) and XPS C1s peak-fitted52 components $\mathrm{N}-\mathrm{C}=\mathrm{O}+\mathrm{C}-\mathrm{N}$ in function of sintering temperature. g XPS C1s peak fitting for sample at $25 \mathrm{oC}$ and $\mathrm{h}$ XPS N1s peak fitting for samples at $25 \mathrm{oC}$ and $230 \mathrm{oC}$. Details of the XPS peak-fitting parameters can be found in Supplementary Tables ST1 and ST2.

a

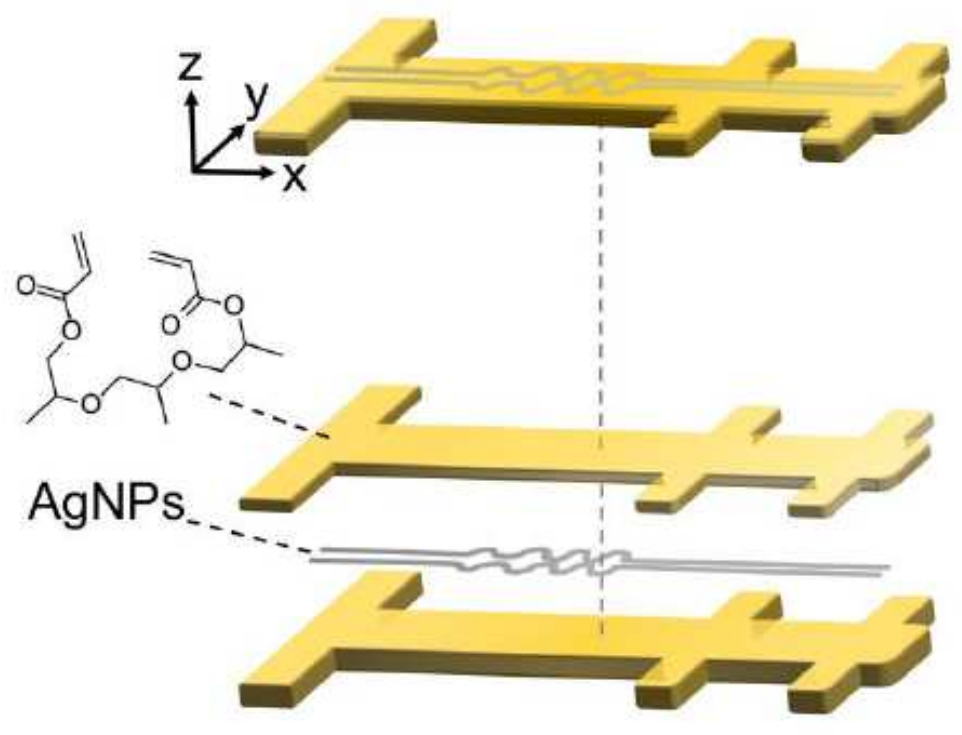

C

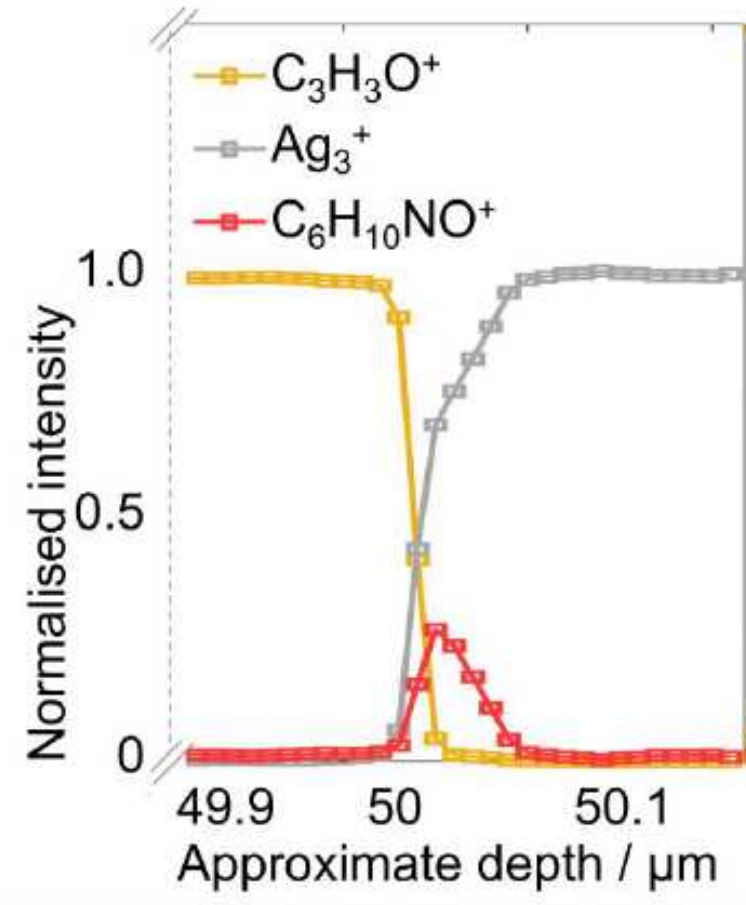

b
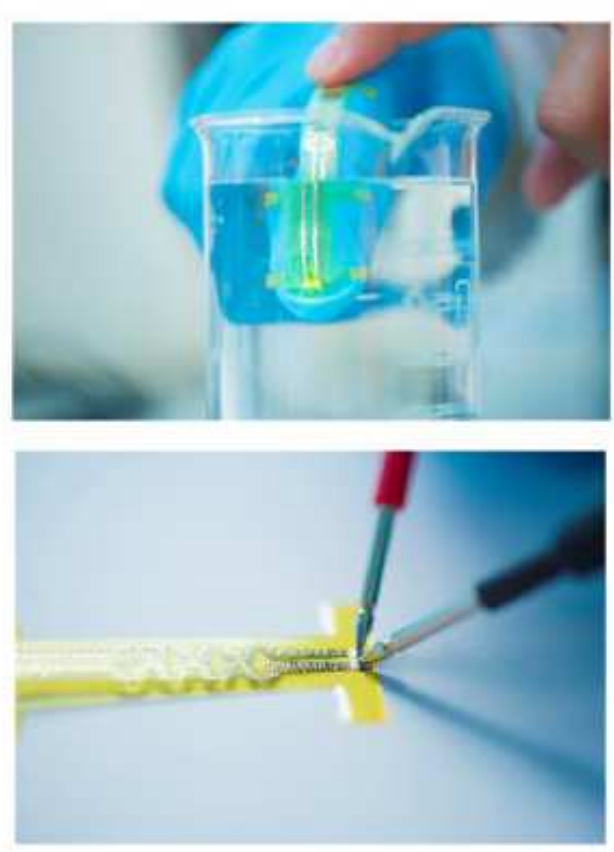

e

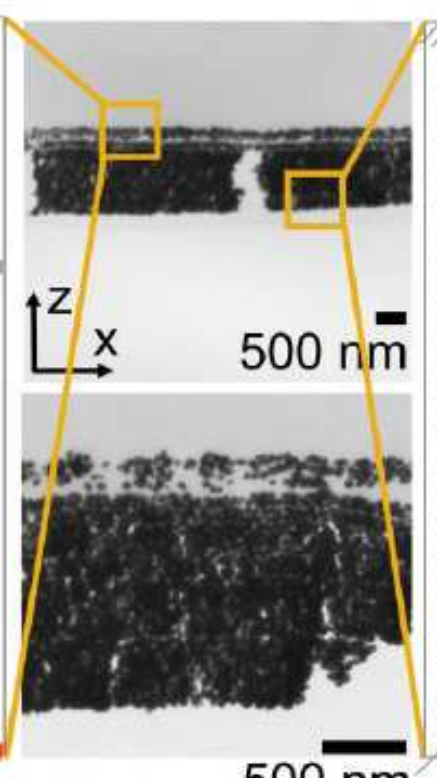
$500 \mathrm{~nm}$

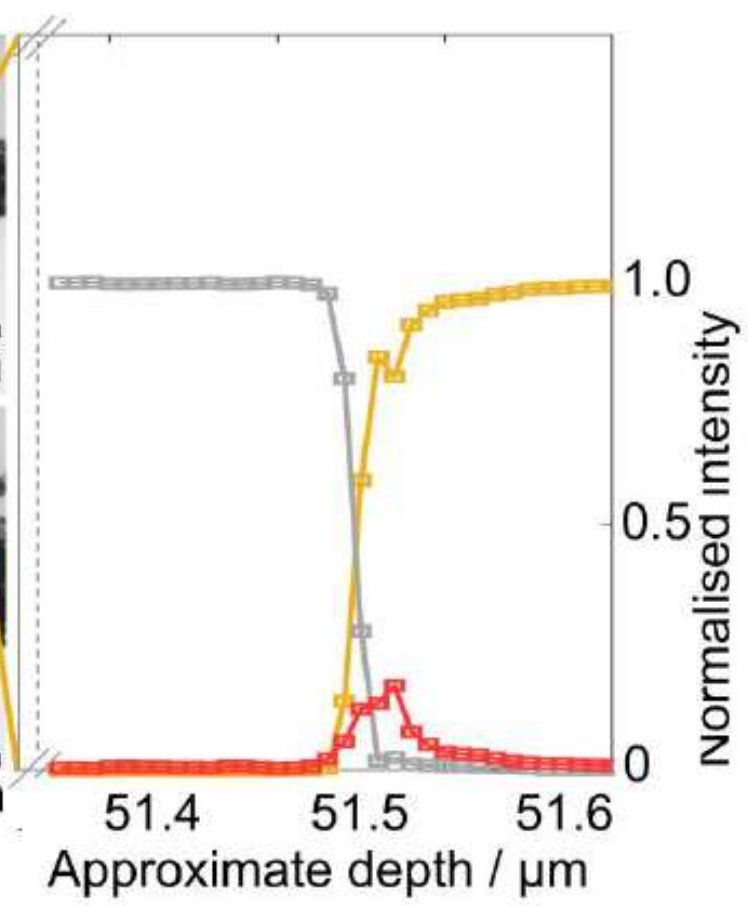

\section{Figure 5}

Presence of residual stabiliser in a multi-material inkjet 3D printed encapsulated strain sensor. a Schematic showing the layer structure of the device. b photographs showing that encapsulation enables 
the use of the device under water. ToF-SIMS depth profile results at the $c$ top and e bottom interface. The dielectric material is TPGDA and represented by $\mathrm{C} 3 \mathrm{H} 30+$. PVP is represented by $\mathrm{C} 6 \mathrm{H} 10 \mathrm{NO}+\mathrm{d}$ TEM micrographs of a cross section.

\section{Supplementary Files}

This is a list of supplementary files associated with this preprint. Click to download.

- TrindadeatalOct2020Supplementary.pdf 